\title{
Semantic competition between hierarchically related words during speech planning
}

\author{
ANSGAR HANTSCH and JÖRG D. JESCHENIAK \\ University of Leipzig, Leipzig, Germany \\ and \\ HERBERT SCHRIEFERS \\ Radboud University, Nijmegen, The Netherlands
}

\begin{abstract}
There is overwhelming evidence that during speech planning semantically related words become lexically activated and compete for selection with the to-be-produced target word. The vast majority of this evidence stems from studies using the picture-word task, in which a distractor word (e.g., bird) drawn from the same semantic category as the target (e.g., fish) was shown to inhibit the picture-naming response more strongly than did an unrelated distractor word. By contrast, corresponding evidence from distractor words (e.g., carp) bearing a hierarchical relation to the target (e.g., fish) is sparse and inconclusive. In the present study, we investigated effects of subordinate-level distractors during basiclevel naming and effects of basic-level distractors during subordinate-level naming. Hierarchically related distractors were found to inhibit the naming response in both situations. This pattern of results did not depend on whether the pictures were preferably named at the basic level or at the subordinate level. The results suggest that hierarchically related name alternatives compete for selection.
\end{abstract}

In order to name an object, speakers must identify it, select the appropriate name from a number of entries in their mental lexicons, and activate the corresponding phonological form, which is finally to be converted into an articulatory code. Models of speech production (see, e.g., Dell, 1986; Levelt, Roelofs, \& Meyer, 1999) as well as more specific models of object naming (see, e.g., Humphreys \& Forde, 2001; Humphreys, Lamote, \& Lloyd-Jones, 1995; Humphreys, Riddoch, \& Quinlan, 1988; Johnson, Paivio, \& Clark, 1996) assume that several lexical representations become activated during object naming (i.e., they act as a so-called semantic cohort; Levelt et al., 1991, p. 123). The picture of a dog, for example, activates not only the word dog but also semantically related words (e.g., cat, horse, fish), due either to perceptual overlap or to spread of activation through a conceptual-lexical network). ${ }^{1}$ It is assumed that these coactivated words then compete for selection with the target. Whether this lexical coactivation is restricted to early processes or is maintained throughout the production process, including the retrieval of word

This research was supported by German Research Council Grants DFG JE229/2-3 and DFG JE229/6-1. We thank Gary Dell, Wido La Heij, and two anonymous reviewers for their helpful comments on earlier versions of this article. Many thanks to Nadine Angermann, Birte Forstmann, Kati Klische, Susanne Lamm, Ursula Luserke, Jutta Müller, and Madlen Paucke for their help in data collection. Correspondence concerning this article should be addressed to A. Hantsch, University of Leipzig, Seeburgstrasse 14-20, D-04103 Leipzig, Germany (e-mail: hantsch@uni-leipzig.de). forms, is still under debate and is not the focus of this article.

Strong support for the notion of lexical competition among semantically related words stems from pictureword interference studies. It has been shown numerous times that a (to-be-ignored) distractor word (e.g., bird) that is semantically related to the target (e.g., fish) inhibits naming responses more strongly than does a semantically unrelated distractor word (e.g., tree). Typically, this socalled semantic interference effect is obtained when target picture and distractor are presented simultaneously or in close temporal succession (with distractor onset either preceding or following picture onset by about $150 \mathrm{msec}$; see MacLeod, 1991, for a review). The effect has been observed with visual distractors (see, e.g., Damian \& Martin, 1999; Glaser \& Düngelhoff, 1984; Lupker, 1979; Rosinski, 1977; Starreveld \& La Heij, 1995; Underwood, 1976) as well as with auditory distractors (see, e.g., Damian \& Martin, 1999; Jescheniak, Schriefers, \& Hantsch, 2001; Schriefers, Meyer, \& Levelt, 1990). It is assumed that it reflects lexical rather than conceptual processing, since the effect disappears if the lexical naming task is replaced by a nonlexical conceptual task (see, e.g., Damian \& Bowers, 2003; Schriefers et al., 1990). ${ }^{2}$ The semantic interference effect is interpreted as follows: The visual stimulus (e.g., a picture of a fish) activates the corresponding concept (e.g., FISH) and also a number of semantically related concepts (e.g., BIRD, DOG). This coactivation of concepts might come about as a result of either the visual similarity of structural representations associated with these con- 
cepts (see, e.g., Humphreys \& Forde, 2001) or the spread of activation along established links within the conceptual system (see, e.g., Roelofs, 1992). The latter case is illustrated by the simplified model of the conceptual-lexical system depicted in Figure 1.

Once a concept is activated, activation traverses the system along hardwired links. For example, the picture of a fish activates the concept FISH. From there, activation spreads via the superordinate concept ANIMAL to semantically related concepts such as BIRD. In addition, some models consider that activation also spreads along direct links between concepts at the same level-that is, coordinated concepts such as FISH and BIRD (cf. Levelt et al., 1999). These activated concepts also activate abstract lexical representations to which they are connected-socalled lemma representations coding the corresponding words' syntactic (and possibly lexical-semantic) information (see Levelt et al., 1999; Vigliocco, Vinson, Martin, \& Garrett, 1999). This is the level to which the semantic interference effect is attributed (but see note 2). Semantic interference results from the fact that additional activation is given to a nontarget lemma that is already activated through the perceptual system. Thus, the semantically related nontarget lemma becomes a stronger competitor than any nontarget lemma that is activated only by an unrelated distractor (e.g., tree), and thus the selection of the target lemma is slowed down. In other words, semantic interference in the picture--word task is taken as an index of lexical competition.
The semantic interference effect has been reported time and again and can be regarded as a basic finding of the picture-word interference paradigm. However, in the vast majority of studies participants named objects at the basic level (e.g., fish; see Rosch, Mervis, Gray, Johnson, \& Boyes-Braem, 1976) and used semantically related distractor words drawn from the same level of abstraction (e.g., bird). In the remainder of this article, this interference effect is referred to as semantic within-level interference, indexing lexical competition among words denoting entities at the same level of abstraction.

The model in Figure 1 (see also Jescheniak \& Levelt, 1994; Levelt et al., 1999; Roelofs, 1992), however, suggests that lexical competition should have a broader scope, at least as long as lexical selection depends exclusively on the relative activation of the different nodes without any additional mechanisms that explicitly prevent betweenlevels competition (as proposed, for example, by Roelofs, 1992; see also Costa, Mahon, Savova, \& Caramazza, 2003 , for a similar assumption). Spread of activation within the conceptual network will ultimately result in an activated semantic cohort that also includes words denoting entities at different levels of abstraction. It most likely includes superordinate words (e.g., animal); according to the model assumptions outlined previously, activation of superordinate concepts is a consequence of traversing the indirect pathway connecting semantically coordinated concepts via a common superordinate. The set of activated concepts and words can also be assumed to include

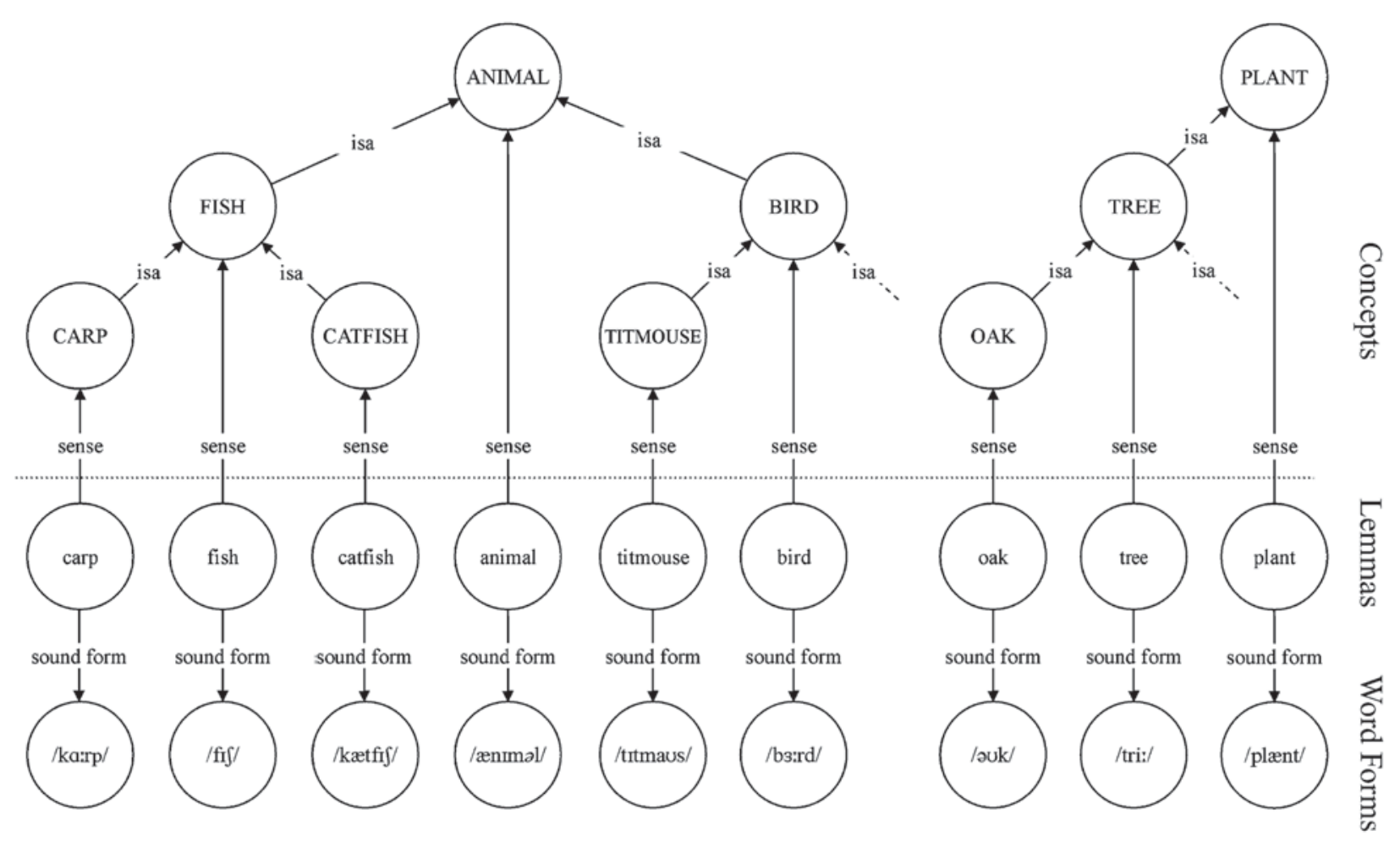

Figure 1. Fragment from the German production lexicon. Isa, is an instance of. Arrows indicate the type or relation only, not the flow of activation. 
subordinate concepts and the corresponding words (e.g., carp). In particular, this should be the case when the visual stimulus contains sufficient detail for identification at this level. Activation of superordinate and subordinate concepts by a basic-level concept requires the traversal of only one link. Such one-step priming is (minimally) also needed to account for the well-documented coactivation of semantically coordinated concepts at the basic level, if it occurs via direct links. If one does not subscribe to the idea of direct links between coordinated concepts, such coactivation must occur by mediation via the superordinate concept. In other words, when one applies the same mechanism that is assumed to underlie semantic withinlevel interference, one should expect the same type of competition between levels. Thus, a semantically related distractor word (e.g., carp) from a different level of abstraction than the target name (e.g., fish) should produce similar effects as a distractor word from the same level of abstraction as the target in the picture-word interference paradigm (e.g., bird). This between-levels interference effect should be symmetrical, in qualitative terms. That is, during basic-level naming a distractor denoting the subordinate name of an object should inhibit the naming response more strongly than an unrelated distractor, and the same should be the case during subordinate-level naming for a distractor denoting the basic-level name of an object (see Vitkovitch \& Tyrrell, 1999, for similar predictions). The size of the effects may differ as a result, for example, of name preference. However, the effects should take the same direction and surface as interference.

Surprisingly, whereas numerous studies have unambiguously demonstrated semantic within-level interference (but see Roelofs, 1992, 1993), the existing studies exploring between-levels competition are sparse and have provided inconclusive results. We will now briefly review these studies. Vitkovitch and Tyrrell (1999) compared between-levels and within-level semantic competition effects using the picture-word paradigm. Their study replicated the within-level interference effect for basiclevel naming (e.g., target, snake; distractor, lizard) and extended this finding to subordinate-level naming (e.g., target, cobra; distractor, adder). These results are in line with the standard findings in the picture-word interference paradigm and indicate that semantic within-level interference is obtained for basic- and subordinate-level naming alike. Nevertheless, in a second experiment the authors also found semantic between-levels facilitation using the same set of pictures. A distractor denoting the basic-level name of the depicted object (e.g., snake) facilitated subordinate-level naming (e.g., cobra) relative to an unrelated distractor. Clearly, this finding is in conflict with the predictions derived above and raises questions of how the lexical competition observed for within-level distractors is prevented for between-levels distractors. We will return to this issue in the General Discussion.

A second study of semantic between-levels competition effects was presented by Roelofs (1992). Participants named objects at the basic level (e.g., tree), and distractors were either from the superordinate (e.g., plant) or the sub- ordinate (e.g., oak) level. In addition, a condition with within-level distractors (e.g., bush) was used. At SOA $-100 \mathrm{msec}$, between-levels distractors tended to facilitate the naming response (8-msec facilitation for superordinatelevel distractors and 29-msec facilitation for subordinatelevel distractors). Surprisingly, however, a $21-\mathrm{msec}$ facilitation was also obtained for within-level distractors, for which the vast majority of studies had observed interference effects. The reason for this difference is not yet fully understood. Roelofs's (1992) original explanation that semantically related distractors would lead to interference only if the distractor is also part of the response set was challenged by more recent studies (see Caramazza \& Costa, 2000) and is not in line with a number of studies in which semantic interference was also obtained from distractors not included in the response set (see, e.g., Damian \& Bowers, 2003; Damian \& Martin, 1999; Jescheniak et al., 2001; Jescheniak, Schriefers, \& Hantsch, 2003; Schriefers et al., 1990; Starreveld \& La Heij, 1995). It might be that semantic (within-level and between-levels) facilitation is confined to a restricted set of situations in which a small number of target utterances and/or a large number of response repetitions makes it possible to maintain all targets in short-term memory, preventing other elements from competing with elements of this set (see Caramazza \& Costa, 2000; Levelt et al., 1999; Roelofs, 2001).

Until now, we have been discussing studies in which between-levels effects for basic-level and subordinatelevel naming were investigated. The main conclusion is that the only two existing studies of such between-levels effects during picture naming provide evidence that appears to contradict the predictions that can be derived from current theories of picture naming and speech production. Both studies report semantic facilitation for betweenlevels distractors, yet they also show a divergence in that the study by Vitkovitch and Tyrrell (1999) replicated the standard within-level interference effect for basic-level naming and extended it to subordinate-level naming, whereas Roelofs (1992) reported facilitative effects also for within-level distractors.

The situation appears to be somewhat different for studies in which between-levels effects for picture categorization were investigated. In such studies, participants name an object (e.g., a hammer) by means of the corresponding superordinate category name (e.g., tool) while a distractor is presented that denotes either the basic-level name of the object (e.g., hammer) or the basic-level name of some other exemplar of the corresponding category (e.g., saw; see, e.g., Costa et al., 2003; Glaser \& Düngelhoff, 1984). These studies consistently show facilitation. However, a closer look at the specific task strongly suggests that picture categorization and picture naming differ in at least one important respect and therefore do not necessarily involve the same task requirements. During picture naming, the necessary information can be retrieved directly from the visual information, whereas picture categorization requires at least some extra conceptual processing in order for the superordinate category name to be derived. This notion is supported by evidence suggesting that the 
superordinate level has a somewhat different status than the basic level and the subordinate level.

It has been shown that superordinate-level names are mainly used to name groups of objects from the same basic-level categories (e.g., animals, furniture, tools) but hardly ever to name single objects (Jolicœur, Gluck, \& Kosslyn, 1984; Murphy \& Wisniewski, 1989; Rosch et al., 1976). Furthermore, superordinate-level names are typically learned (produced and comprehended) later in life than basic- and subordinate-level names (see, e.g., J. M. Clark \& Johnson, 1994; Rosch et al., 1976). Finally, categorization remains considerably slower than naming throughout life (Costa et al., 2003; Irwin \& Lupker, 1983; Jolicœur et al., 1984; Lin, Murphy, \& Shoben, 1997; Smith \& Magee, 1980; Wingfield, 1967).

For the time being, we can conclude that between-levels effects obtained with the picture categorization task (involving the basic level and the superordinate level) are not necessarily directly comparable to between-levels effects obtained for the basic level and the subordinate level. Therefore, we will restrict our discussion to basic-level and subordinate-level naming. If the semantic facilitation effect obtained during picture categorization indeed relies on the use of between-levels distractors (as has been argued by Costa et al., 2003), then semantic between-levels facilitation should also be present during basic- and subordinate-level naming. If, however, some special feature of the picture categorization task is responsible for the observed facilitation effects, these effects should not be obtained during basic- or subordinate-level naming. Notice that semantic between-levels inhibition obtained during basic- and subordinate-level naming would support the likelihood of an account that places the locus of the semantic facilitation effect for superordinate naming in the presence of basic-level distractors at a differentpossibly nonlexical-level than the semantic interference effect (see, e.g., Bloem \& La Heij, 2003; Kuipers \& La Heij, 2004). From the hypotheses presented above, it appears that there are good reasons not to treat picture categorization tasks and picture-naming tasks as one and the same type of task. In the present work, we focus on the question of whether between-levels distractors produce semantic interference during picture naming, as predicted by our extrapolation of current theories of speech production (see also Vitkovitch \& Tyrrell, 1999, for similar predictions), or whether lexical between-levels competition follows different principles than lexical within-level competition (as suggested by the results of Vitkovitch \& Tyrrell, 1999; see also Costa et al., 2003).

To this end, we studied the impact of subordinate-level distractors during basic-level naming (Experiments 1 and 2) and the impact of basic-level distractors during subordinate-level naming (Experiment 3). Since the preferred naming level for the materials might have an impact on semantic competition, different sets of pictures were used for Experiments 1-3 and for Experiments 4-5. In Experiments 1-3, we used line drawings with their preferred names located at the basic level of abstraction (e.g., the drawing of a carp with the preferred name fish). In Experiments 4 and 5, photo-realistic stimuli with their preferred names at the subordinate level of abstraction were used (e.g., the picture of a shark with the preferred name shark). The preferred naming levels for the two sets of experimental materials were established in two norming studies. In the first, in which line drawings of simple objects were used, only items that the majority of participants spontaneously named with their basic-level names were selected. These materials were used in Experiments $1-3$. In the second norming study, in which photorealistic pictures of objects were used, only items that the majority of participants spontaneously named with their subordinate-level names were selected. These materials were used in Experiments 4 and 5. We followed relevant examples of basic-level names from the literature as much as possible and constructed the materials following these examples to the extent possible. Note that the participants' responses in the pretest were not used to determine which names should be considered basic-level names.

Contrasting the results of Experiments 1-3 with those of Experiments 4 and 5 will allow us to investigate whether a name preference at the basic level versus the subordinate level affects the pattern of results, or whether the results generalize across differences in the preferred level of naming.

\section{EXPERIMENT 1}

In Experiment 1, we investigated the effects of subordinatelevel name distractors (e.g., carp) during basic-level naming (e.g., fish). In this and all other experiments, we also tested for the phonological activation of the target name by comparing the effects of phonologically related distractors (e.g., film) to the effects of unrelated distractors. Such distractors are known to facilitate the naming response reliably (see, e.g., Meyer \& Schriefers, 1991; Schriefers et al., 1990); the motivation for including these conditions was to demonstrate the sensitivity of the experiment for the case in which no semantic between-levels effect should be obtained.

\section{Method}

Participants. Thirty-two participants were tested in this experiment. They were paid $€ 7$ (approximately US \$7). In this and the following experiments, the participants were native speakers of German. Most of them were students from the University of Leipzig. They had no known hearing deficits and normal or corrected-tonormal vision. Participants with overall error rates exceeding $10 \%$ were replaced. No participant took part in more than one of the experiments reported in this article.

Materials. We used black-and-white line drawings of simple objects, which contained sufficient detail that they could be named at either the basic level (e.g., fish) or the subordinate level (e.g., carp). For the 24 items used, normed name preference was located at the basic level, as revealed in a pretest. The purpose of the pretest was to ensure that the preferred names of the pictures, or entry points (Jolicœur et al., 1984), were located on the basic level (cf. Rosch et al., 1976). We predefined the basic level as a level of abstraction intermediate between a category label that is most frequently used 
to refer to a collection of objects (e.g., animal) and the name for a specific instance of a member of such a category (e.g., poodle). In this pretest, 60 line drawings from 15 basic-level categories were presented to an independent sample of 80 participants. Each participant viewed only one member of each basic-level category. The participants were asked to write down the first appropriate name that came to mind in response to each picture. The experimental items were selected according to the following general criteria: (1) dominance of the intended basic-level name - that is, the participants provided the intended basic-level name in the majority of cases $(M=82.4 \%, S D=10.9 \%$; range, $63.3 \%-100.0 \%)$; (2) consistency of usage of the intended basic- and subordinate-level names - that is, the participants provided the intended basic- or subordinate-level name in the majority of cases $(M=93.1 \%, S D=6.7 \%$; range, $79.3 \%-100.0 \%$ ); (3) absence of initial phonological overlap between basic- and subordinate-level names; and (4) restriction to items with monomorphemic basic- and subordinate-level names. The 24 selected objects belonged to 12 basic-level categories, with 2 objects from each category. For each object, two distractors were chosen. One distractor denoted the object's (nonpreferred) subordinate-level name, and the other was phonologically related to the basic-level target name in that it shared, at a minimum, the initial vowel or consonant-vowel segment with the basic-level name, but had no obvious semantic relation with it. Two unrelated control conditions were created by reassigning the related and unrelated distractors to the experimental pictures. See Appendix A for a complete list of the experimental materials.

The pictures were sized to fill a square of about $11 \times 11 \mathrm{~cm}$ $(220 \times 220$ pixels $)$. The acoustic distractor words were spoken by a female native speaker of German. Subordinate-level name distractors varied in duration from 739 to $1,263 \mathrm{msec}$, with an average of $981 \mathrm{msec}(S D=116 \mathrm{msec})$. Phonologically related distractors varied in duration from 731 to $1,006 \mathrm{msec}$, with an average of $898 \mathrm{msec}$ $(S D=75 \mathrm{msec})$. All auditory materials were digitized at a sampling rate of $22 \mathrm{KHz}$ for presentation during the experiment. An additional set of six objects with appropriate distractors was selected, to be used in warm-up trials.

Design. There were two pairs of critical comparisons of distractor conditions (subordinate-level name vs. unrelated name, and phonologically related name vs. phonologically unrelated name). Stimulus onset asynchrony (SOA) was varied in four steps $(0,100,200$, and $300 \mathrm{msec}$ ). Thus, there were two completely crossed variables: the four-level variable of SOA, and the two-level variable of relatedness. All variables were tested within participants.

SOAs were blocked with the sequence of SOA blocks counterbalanced across participants using a Latin square procedure. Sixteen different experimental lists were created according to the following general criteria: (1) Repetitions of a target picture were separated by at least eight intervening trials, (2) repetitions of target pictures belonging to the same superordinate category were separated by at least one intervening trial, (3) repetitions of identical distractors were separated by at least four intervening trials, (4) there were no more than three consecutive trials with the same distractor condition, (5) there were no more than four consecutive trials with related distractors conditions, and (6) repetitions of distractors with identical onsets were separated by at least one intervening trial. Each experimental block began with six warm-up items. The 16 experimental lists were all used equally often.

Procedure. Each participant was tested individually in a session lasting about $1 \mathrm{~h}$. The participant was comfortably seated in a dimly lit room, separated from the experimenter by a partition wall. The visual stimuli were presented on a 37.4-cm (17-in.) computer screen as black line drawings on a light gray background. Viewing distance was about $60 \mathrm{~cm}$. The presentation of the visual and auditory stimuli and the online collection of the data were controlled by a computer with a Pentium processor (Intel Corporation, Santa Clara, CA). Auditory distractors were presented with headphones at a comfortable listening volume. Speech onset latencies were measured to the closest millisecond with a voice key connected to the computer.

A trial was structured as follows. The target picture was presented in the center of the screen for $800 \mathrm{msec}$. Auditory distractors were presented simultaneously with the onset of the target picture (SOA $0 \mathrm{msec}$ ), $100 \mathrm{msec}$ later (SOA $100 \mathrm{msec}$ ), $200 \mathrm{msec}$ later (SOA $200 \mathrm{msec}$ ), or $300 \mathrm{msec}$ later (SOA $300 \mathrm{msec}$ ). The participants named the target picture as quickly as possible with the basic-level name. Speech onset latencies were measured from the onset of the target picture. The total length of one trial was about $4 \mathrm{sec}$.

The actual experiment consisted of four parts: a study phase, a practice phase, the main session, and a follow-up session. During the study phase, the participants studied a written instruction booklet that emphasized the importance of both the speed and the accuracy of their responses. The participants also received a booklet showing all the experimental pictures. Next to each picture, the depicted object's basic-level name was printed. The participants were instructed to use these names only. Then, two practice blocks were administered, in which the participants named each picture used in the experiment twice. No auditory distractors were presented during the practice phase. The experimenter monitored whether or not the participants used the target names and corrected them if necessary. Then, the main experiment started with the first of four SOA blocks. There were short breaks between these blocks. After the main session, the participants were administered a questionnaire in which they indicated for each experimental picture which name they would prefer in spontaneous naming outside the context of the experiment. ${ }^{3}$

\section{Results and Discussion}

Observations were coded as erroneous and discarded from the reaction time (RT) analyses whenever any of the following conditions held: (1) A picture had not been named with the expected name, (2) a nonspeech sound preceded the target utterance, triggering the voice key, (3) a dysfluency occurred or an utterance was repaired, or (4) a speech onset latency exceeded $3 \mathrm{sec}$. Observations deviating from a participant's and an item's mean by more than two standard deviations were considered as outliers and were also discarded from the RT analyses. Four hundred sixty-two observations $(3.8 \%)$ were marked as erroneous, and 242 observations $(2.0 \%)$ were marked as outliers. These data points were discarded from the RT analyses.

Averaged RTs were submitted to ANOVAs separately for the subordinate-level distractor conditions and the phonological distractor conditions. Statistical analyses involved the variables relatedness (subordinate-level name vs. unrelated name, and phonologically related name vs. phonologically unrelated name) and SOA (0, 100, 200, and $300 \mathrm{msec}$ ). Two complementary analyses were computed, one treating participants and one treating items as a random variable (H. Clark, 1973).

Table 1 displays mean RTs and error rates by SOA and distractor type.

Effects of subordinate-level name distractors. Naming latencies and error rates decreased from SOA $0 \mathrm{msec}$ to SOA $300 \mathrm{msec}$, as reflected in significant SOA effects [for RTs, $F_{1}(3,93)=28.04, M S_{\mathrm{e}}=3,578.52, p<.001$ and $F_{2}(3,69)=101.12, M S_{\mathrm{e}}=711.09, p<.001$; for error rates, $F_{1}(3,93)=2.90, M S_{\mathrm{e}}=1.10, p<.05$ and $\left.F_{2}(3,69)=4.47, M S_{\mathrm{e}}=0.95, p<.01\right]$. Relatedness was 
Table 1

Experiment 1: Mean Reaction Times (in Milliseconds) and Error Rates (\%Error) by SOA and Distractor Type

\begin{tabular}{|c|c|c|c|c|c|c|c|c|}
\hline \multirow[b]{3}{*}{ Distractor } & \multicolumn{8}{|c|}{$\mathrm{SOA}(\mathrm{msec})$} \\
\hline & \multicolumn{2}{|c|}{0} & \multicolumn{2}{|c|}{100} & \multicolumn{2}{|c|}{200} & \multicolumn{2}{|c|}{300} \\
\hline & $M$ & $\%$ Error & $M$ & $\%$ Error & $M$ & $\%$ Error & $M$ & $\%$ Error \\
\hline Sub & 651 & 7.6 & 615 & 5.6 & 557 & 4.8 & 545 & 2.5 \\
\hline Unr & 609 & 3.3 & 588 & 3.9 & 554 & 2.9 & 545 & 4.2 \\
\hline Difference & $+42^{* * * / * *}$ & $+4.3^{* * / * *}$ & $+27^{* * * / *}$ & +1.7 & +3 & $+1.9^{* / *}$ & 0 & $-1.7^{\text {n.s. } / *}$ \\
\hline Pho-Rel & 520 & 2.9 & 511 & 1.8 & 517 & 1.6 & 534 & 3.1 \\
\hline Pho-Unr & 609 & 5.1 & 600 & 3.4 & 560 & 3.5 & 544 & 4.0 \\
\hline Difference & $-89^{* * * / * * *}$ & $-2.2^{\text {n.s. } .^{*}}$ & $-89^{* * * / * * *}$ & $-1.6^{\text {n.s. } .^{*}}$ & $-43^{* * * / * * *}$ & $-1.9^{* / *}$ & $-10^{* * / *}$ & -0.9 \\
\hline
\end{tabular}

Note-The basic-level name is the target word. SOA, stimulus onset asynchrony; Sub, subordinate-level name; Unr, unrelated to subordinate-level name; Pho-Rel, phonologically related to the basic-level target name; Pho-Unr, phonologically unrelated to the basic-level target name. Positive difference scores reflect interference, and negative difference scores reflect facilitation. The significance of these scores is indicated by superscripts, in which results from the $t$ tests by participant precede results from the $t$ tests by item. ${ }^{*} p<$ $.05 . \quad{ }^{* *} p<.01 .{ }^{* * *} p<.001$

also significant [for RTs, $F_{1}(1,31)=21.75, M S_{\mathrm{e}}=$ $954.29, p<.001$ and $F_{2}(1,23)=9.25, M S_{\mathrm{e}}=1,626.92$, $p<.01$; for error rates, $F_{1}(1,31)=9.88, M S_{\mathrm{e}}=0.91$, $p<.01$ and $\left.F_{2}(1,23)=8.56, M S_{\mathrm{e}}=1.40, p<.01\right]$, reflecting longer naming latencies and more errors for subordinate-level name distractors in comparison with unrelated distractors. The two variables interacted [for RTs, $F_{1}(3,93)=10.91, M S_{\mathrm{e}}=571.08, p<.001$ and $F_{2}(3,69)=6.77, M S_{\mathrm{e}}=689.59, p<.001$; for error rates, $F_{1}(3,93)=5.32, M S_{\mathrm{e}}=1.05, p<.01$ and $F_{2}(3,69)=$ $\left.5.77, M S_{\mathrm{e}}=1.29, p<.01\right] . t$ tests revealed that longer naming latencies for subordinate-level name distractors were observed only at SOA 0 msec $\left[t_{1}(31)=4.45, p<\right.$ $\left..001 ; t_{2}(23)=3.65, p<.01\right]$ and SOA $100 \mathrm{msec}\left[t_{1}(31)=\right.$ $4.68, p<.001 ; t_{2}(23)=2.49, p<.05$; all other $t \mathrm{~s}<1$ ], and that more errors with related distractors were found at SOA 0 msec $\left[t_{1}(31)=3.57, p<.01 ; t_{2}(23)=3.14, p<\right.$ $.01]$ and SOA $200 \mathrm{msec}\left[t_{1}(31)=2.13, p<.05 ; t_{2}(23)=\right.$ $2.08, p<.05]$. At SOA $300 \mathrm{msec}$, slightly more errors with unrelated distractors were obtained; however, this effect was not confirmed in the participant analysis $\left[t_{1}(31)=-1.89, p=.068 ; t_{2}(23)=-2.41, p<.05\right]$. At SOA $100 \mathrm{msec}$, no significant effects for error rates were obtained $\left[t_{1}(31)=1.47, p>.10 ; t_{2}(23)=1.64, p>.10\right]$.

Effects of phonologically related distractors. Naming responses were faster at longer SOAs, as reflected in a reliable SOA effect $\left[F_{1}(3,93)=11.69, M S_{\mathrm{e}}=926.68\right.$, $\left.p<.001 ; F_{2}(3,69)=19.79, M S_{\mathrm{e}}=405.05, p<.001\right]$. Phonologically related distractors facilitated the naming response, yielding a significant effect of relatedness for naming latencies $\left[F_{1}(1,31)=154.46, M S_{\mathrm{e}}=1,374.46\right.$, $\left.p<.001 ; F_{2}(1,23)=155.47, M S_{\mathrm{e}}=1,028.91, p<.001\right]$ and error rates $\left[F_{1}(1,31)=13.72, M S_{\mathrm{e}}=0.74, p<.01\right.$; $\left.F_{2}(1,23)=8.58, M S_{\mathrm{e}}=1.58, p<.01\right]$. In the RT analysis, relatedness interacted with SOA $\left[F_{1}(3,93)=43.79\right.$, $M S_{\mathrm{e}}=546.98, p<.001 ; F_{2}(3,69)=58.30, M S_{\mathrm{e}}=$ $302.78, p<.001]$, reflecting the fact that more facilitation was obtained at short SOAs than at long SOAs [for SOA $0 \mathrm{msec}, t_{1}(31)=-10.35, p<.001$ and $t_{2}(23)=-10.56$, $p<.001$; for SOA $100 \mathrm{msec}, t_{1}(31)=-9.80, p<.001$ and $t_{2}(23)=-12.55, p<.001$; for SOA $200 \mathrm{msec}$, $t_{1}(31)=-9.55, p<.001$ and $t_{2}(23)=-8.29, p<.001$; for SOA $300 \mathrm{msec}, t_{1}(31)=-2.80, p<.01$ and $t_{2}(23)=$ $-2.70, p<.05]$.

Subordinate-level name distractors inhibited basiclevel naming responses, whereas phonologically related distractors facilitated naming responses. The semantic between-levels interference effect suggests that subordinatelevel names not only become activated during basic-level naming but also compete for selection with these basiclevel names, in line with the predictions outlined above. However, before drawing strong conclusions from this finding, we need to address one caveat. It might be that this competition was induced by the fact that two exemplars from each basic-level category (e.g., the picture of a carp and the picture of a catfish, both of which had to be named with the word fish) were included in the experiment. This situation might have drawn the participants' attention to the pictures' subordinate-level names, thereby causing lexical activation and competition that might otherwise not have been present. In Experiment 2, we tested for this possibility.

\section{EXPERIMENT 2}

Experiment 2 was a replication of Experiment 1, with the difference that each participant viewed only one exemplar from each basic-level category. If the presence of two exemplars from the same basic-level category in Experiment 1 had induced the semantic between-levels interference effect, the corresponding effect should be reduced or absent in Experiment 2.

\section{Method}

Participants. Thirty-two participants were tested. Sixteen participants were tested with one half of the materials, and 16 were tested with the remaining half of the materials.

Materials. The materials were identical to those used in Experiment 1 . They were divided into two subsets in such a way that each subset contained exactly one picture from each of the 12 basic-level categories. In addition to the 12 experimental pictures in each subset, 12 filler pictures (the same for both subsets) were used to keep the size of the item set comparable to the size of the set used in Experiment 1. 
Design and Procedure. The design and the procedure were identical to those used in Experiment 1.

\section{Results and Discussion}

The raw data were treated in the same way as in Experiment 1 . In all, 288 observations (4.7\%) were marked as erroneous and 111 observations $(1.8 \%)$ were marked as outliers. These data points were discarded from the RT analyses.

Table 2 displays mean RTs and error rates by SOA and distractor type.

Effects of subordinate-level name distractors. Naming latencies decreased from the short SOAs to the long SOAs, yielding a significant SOA effect $\left[F_{1}(3,93)=\right.$ $25.82, M S_{\mathrm{e}}=2,489.74, p<.001 ; F_{2}(3,69)=52.91$, $\left.M S_{\mathrm{e}}=943.64, p<.001\right]$. Relatedness was also significant $\left[F_{1}(1,31)=9.66, M S_{\mathrm{e}}=13,865.06, p<.01 ; F_{2}(1,23)=\right.$ $\left.8.20, M S_{\mathrm{e}}=1,125.35, p<.01\right]$, reflecting slower naming responses for subordinate-level name distractors in comparison with unrelated distractors. The interaction of this variable with SOA was reliable $\left[F_{1}(3,93)=5.84, M S_{\mathrm{e}}=\right.$ $1,132.32, p<.01 ; F_{2}(3,69)=5.83, M S_{\mathrm{e}}=778.44, p<$ $.01]$, and $t$ tests revealed that interference was restricted to SOAs $0 \mathrm{msec}$ and $100 \mathrm{msec}$ [for SOA $0 \mathrm{msec}, t_{1}(31)=$ $4.88, p<.001$ and $t_{2}(23)=3.77, p<.001$; for SOA $100 \mathrm{msec}, t_{1}(31)=2.08, p<.05$ and $t_{2}(23)=2.88, p<$ .01 ; all other $t \mathrm{~s}<1]$. The analysis of error rates revealed no significant effects.

Effects of phonologically related distractors. Naming latencies again decreased from the short SOAs to the long SOAs, yielding a significant SOA effect $\left[F_{1}(3,93)=\right.$ $4.13, M S_{\mathrm{e}}=1,565.29, p<.01 ; F_{2}(3,69)=7.42, M S_{\mathrm{e}}=$ $743.04, p<.001]$. Overall, phonologically related distractors shortened naming latencies and reduced error rates in comparison with unrelated distractors, yielding significant effects of relatedness [for RTs, $F_{1}(1,31)=124.54$, $M S_{\mathrm{e}}=2,367.02, p<.001$ and $F_{2}(1,23)=145.81, M S_{\mathrm{e}}=$ $1,493.40, p<.001$; for error rates, $F_{1}(1,31)=5.60$, $M S_{\mathrm{e}}=0.47, p<.05$ and $F_{2}(1,23)=6.12, M S_{\mathrm{e}}=0.58$, $p<.05]$. Relatedness interacted with SOA in the analysis of naming latencies $\left[F_{1}(3,93)=25.90, M S_{\mathrm{e}}=924.26\right.$, $\left.p<.001 ; F_{2}(3,69)=21.79, M S_{\mathrm{e}}=810.91, p<.001\right]$, reflecting the fact that facilitation was strongest at the short SOAs and weakest at the long SOAs [for SOA $0 \mathrm{msec}$, $t_{1}(31)=-10.58, p<.001$ and $t_{2}(23)=-9.20, p<$ .001 ; for SOA $100 \mathrm{msec}, t_{1}(31)=-10.81, p<.001$ and $t_{2}(23)=-10.93, p<.001$; for SOA $200 \mathrm{msec}, t_{1}(31)=$ $-4.76, p<.001$ and $t_{2}(23)=-5.64, p<.001$; for SOA $300 \mathrm{msec}, t_{1}(31)=-3.42, p<.01$ and $t_{2}(23)=-3.11$, $p<.01]$.

Again, semantic interference was obtained with between-levels distractors. As has been outlined above, one could suspect that the presence of a second exemplar with the same basic-level name as in Experiment 1 could have rendered the objects' subordinate-level names more salient, making them stronger competitors than they would otherwise be. However, Experiment 2 showed that this was clearly not the case. In fact, supplementary ANOVAs with the additional variable of experiment confirmed that the interference effect from subordinate-level name distractors was of the same size in Experiments 1 and 2 (for RTs, experiment $\times$ relatedness, $F_{1 \& 2}<1$; experiment $\times \mathrm{SOA} \times$ relatedness, $F_{1 \& 2}<1$ ).

In the experiments reported thus far, the participants named objects with their preferred basic-level names while ignoring distractor words denoting their subordinate-level names. Regardless of the presence of one or two exemplars from the same basic-level category, semantic betweenlevels interference was observed. Distractors denoting the subordinate-level names of the pictures inhibited basiclevel naming responses. This suggests that these subordinatelevel names become lexically activated and compete for selection with the target name, in line with the predictions derived in the introduction.

This finding contrasts with the semantic betweenlevels facilitation effect observed by Vitkovitch and Tyrrell (1999). However, these authors had participants name objects at the subordinate level while ignoring distractor words denoting their basic-level names, whereas in Experiments 1 and 2 our participants named objects at

Table 2

Experiment 2: Mean Reaction Times (in Milliseconds) and Error Rates (\%Error) by SOA and Distractor Type

\begin{tabular}{|c|c|c|c|c|c|c|c|c|}
\hline \multirow[b]{3}{*}{ Distractor } & \multicolumn{8}{|c|}{$\mathrm{SOA}(\mathrm{msec})$} \\
\hline & \multicolumn{2}{|l|}{0} & \multicolumn{2}{|c|}{100} & \multicolumn{2}{|c|}{200} & \multicolumn{2}{|c|}{300} \\
\hline & $M$ & $\%$ Error & $M$ & $\%$ Error & $M$ & $\%$ Error & $M$ & $\%$ Error \\
\hline Sub & 656 & 7.6 & 641 & 6.3 & 579 & 4.4 & 575 & 5.5 \\
\hline Unr & 617 & 5.5 & 616 & 3.4 & 583 & 4.7 & 575 & 5.7 \\
\hline Difference & $+39^{* * * / * *}$ & +2.1 & $+25^{* / * *}$ & $+2.9^{* / \mathrm{n} . \mathrm{s}}$ & -4 & -0.3 & 0 & -0.2 \\
\hline Bas-Rel & 536 & 3.9 & 530 & 3.4 & 544 & 1.6 & 554 & 2.9 \\
\hline Bas-Unr & 638 & 3.4 & 629 & 6.0 & 590 & 4.2 & 579 & 5.0 \\
\hline Difference & $-102^{* * * / * * *}$ & +0.5 & $-99^{* * * / * * *}$ & $-2.6^{\text {n.s./* }}$ & $-46^{* * * / * * *}$ & $-2.6^{* / * *}$ & $-25^{* * / * *}$ & -2.1 \\
\hline
\end{tabular}

Note-The basic-level name is the target word. SOA, stimulus onset asynchrony; Sub, subordinate-level name; Unr, unrelated to subordinate-level name; Bas-Rel, phonologically related to the basic-level target name; Bas-Unr, phonologically unrelated to the basic-level target name. Positive difference scores reflect interference, and negative difference scores reflect facilitation. The significance of these scores is indicated by superscripts, in which results of the $t$ tests by participant precede results from the $t$ tests by item. $\quad{ }^{*} p<$ $.05 .{ }^{* *} p<.01 . \quad{ }^{* * *} p<.001$. 
the basic level while hearing the objects' subordinate names as distractors. One could thus hypothesize that semantic between-levels effects are not symmetrical: Coactivated subordinate names might compete for selection with the basic-level targets (hence the interference effect in Experiments 1 and 2), whereas basic-level names, though coactivated, do not compete for selection with the subordinate-level targets (hence the facilitation effect in Vitkovitch \& Tyrrell, 1999). This possibility was explored in Experiment 3.

\section{EXPERIMENT 3}

In Experiment 3, we tested subordinate-level naming in the presence of distractors denoting the basic-level names of objects.

\section{Method}

Participants. Thirty-two participants were tested.

Materials. The picture stimuli were identical to those used in Experiment 1 . For each picture, two new distractors were selected. The first distractor denoted the object's basic-level name. These basiclevel name distractors varied in duration from 709 to $1,067 \mathrm{msec}$, with an average of $868 \mathrm{msec}(S D=115 \mathrm{msec})$. The second distractor was phonologically related to the subordinate-level target word. As before, these distractors shared, at a minimum, the initial vowel or consonant-vowel segment with the subordinate-level target name. They varied in duration from 720 to $1,115 \mathrm{msec}$, with an average of $915 \mathrm{msec}(S D=97 \mathrm{msec})$. See Appendix B for a complete list of the experimental materials.

Design. The design was identical to that used in Experiment 1.

Procedure. The procedure was identical to that used in Experiment 1 , with the following exceptions. In the picture booklet, the basic-level names were replaced by the subordinate-level names, and the participants were instructed to name the target pictures as quickly as possible using these names. The amount of practice was increased to four to six practice blocks.

\section{Results and Discussion}

The raw data were treated as in the previous experiments. Five hundred forty-four observations (4.4\%) were marked as erroneous, and 211 observations (1.7\%) were marked as outliers. These data points were discarded from the RT analyses.
Table 3 displays mean RTs and error rates by SOA and distractor type.

Effects of basic-level name distractors. Naming latencies decreased from short SOAs to long SOAs, yielding a significant $\mathrm{SOA}$ effect $\left[F_{1}(3,93)=2.87, M S_{\mathrm{e}}=\right.$ $5,055.07, p<.05 ; F_{2}(3,69)=10.70, M S_{\mathrm{e}}=930.22, p<$ $.001]$. Relatedness was also significant in the RT analysis $\left[F_{1}(1,31)=22.76, M S_{\mathrm{e}}=1,176.21, p<.001 ; F_{2}(1,23)=\right.$ $\left.38.84, M S_{\mathrm{e}}=518.33, p<.001\right]$, reflecting longer naming responses with distractors denoting an object's basiclevel name in comparison with naming responses with unrelated distractors. There was no interaction between SOA and relatedness. The analysis of error rates revealed no significant effects.

Effects of phonologically related distractors. Naming latencies decreased from short SOAs to long SOAs, yielding a significant SOA effect $\left[F_{1}(3,93)=3.39, M S_{\mathrm{e}}=\right.$ $6,165.66, p<.05 ; F_{2}(3,69)=17.45, M S_{\mathrm{e}}=869.70$, $p<.001]$. Relatedness was significant for naming latencies $\left[F_{1}(1,31)=118.95, M S_{\mathrm{e}}=2,799.52, p<.001\right.$; $\left.F_{2}(1,23)=74.65, M S_{\mathrm{e}}=3,393.50, p<.001\right]$ and error rates $\left[F_{1}(1,31)=9.04, M S_{\mathrm{e}}=1.08, p<.01 ; F_{2}(1,23)=\right.$ $\left.4.85, M S_{\mathrm{e}}=2.68, p<.05\right]$, reflecting faster and more accurate responses with phonologically related distractors than with unrelated distractors. In the RT analysis, relatedness interacted with SOA $\left[F_{1}(3,93)=8.49, M S_{\mathrm{e}}=\right.$ $799.83, p<.001 ; F_{2}(3,69)=7.37, M S_{\mathrm{e}}=642.68, p<$ $.001]$, reflecting the fact that more facilitation was obtained for short than for long SOAs [for SOA $0 \mathrm{msec}$, $t_{1}(31)=-8.50, p<.001$ and $t_{2}(23)=-7.22, p<$ .001 ; for SOA $100 \mathrm{msec}, t_{1}(31)=-9.30, p<.001$ and $t_{2}(23)=-7.28, p<.001$; for SOA $200 \mathrm{msec}, t_{1}(31)=$ $-7.33, p<.001$ and $t_{2}(23)=-8.24, p<.001$; for SOA $300 \mathrm{msec}, t_{1}(31)=-6.73, p<.001$ and $t_{2}(23)=-5.34$, $p<.001]$.

Experiment 3 showed that distractors denoting an object's basic-level name inhibit subordinate-level naming more than unrelated distractors do. This suggests that basic-level names become lexically activated during subordinate-level naming and compete for selection with the target word. Thus, semantic between-levels interfer-

Table 3

Experiment 3: Mean Reaction Times (in Milliseconds) and Error Rates (\%Error) by SOA and Distractor Type

\begin{tabular}{|c|c|c|c|c|c|c|c|c|}
\hline \multirow[b]{3}{*}{ Distractor } & \multicolumn{8}{|c|}{$\mathrm{SOA}(\mathrm{msec})$} \\
\hline & \multicolumn{2}{|c|}{0} & \multicolumn{2}{|c|}{100} & \multicolumn{2}{|c|}{200} & \multicolumn{2}{|c|}{300} \\
\hline & $M$ & $\%$ Error & $M$ & $\%$ Error & $M$ & $\%$ Error & $M$ & $\%$ Error \\
\hline Bas & 813 & 5.7 & 801 & 4.8 & 785 & 4.0 & 769 & 3.7 \\
\hline Unr & 785 & 4.2 & 774 & 4.2 & 768 & 4.6 & 759 & 4.3 \\
\hline Difference & $+28^{* * / * *}$ & +1.5 & $+27^{* * / * *}$ & +0.6 & $+17^{* / n . s .}$ & -0.6 & +10 & -0.6 \\
\hline Sub-Rel & 743 & 4.2 & 728 & 2.9 & 729 & 3.8 & 722 & 3.7 \\
\hline Sub-Unr & 832 & 5.6 & 818 & 4.4 & 792 & 6.4 & 768 & 4.6 \\
\hline Difference & $-89^{* * * / * * *}$ & -1.4 & $-90^{* * * / * * *}$ & -1.5 & $-63^{* * * / * * *}$ & $-2.6^{* / *}$ & $-46^{* * * / * * *}$ & -0.9 \\
\hline
\end{tabular}

Note-The subordinate-level name is the target word. SOA, stimulus onset asynchrony; Bas, basic-level name; Unr, unrelated to the basic-level name; Sub-Rel, phonologically related to the subordinate-level target name; Sub-Unr, phonologically unrelated to subordinate-level target name. Positive difference scores reflect interference, and negative difference scores reflect facilitation. The significance of these scores is indicated by superscripts, in which results from the $t$ tests by participant precede results from the $t$ tests by item. $\quad{ }^{*} p<.05 .{ }^{* *} p<.01 .{ }^{* * *} p<.001$. 
ence was once more demonstrated, ruling out the possibility that semantic between-levels competition is asymmetrical and confined to basic-level naming. One drawback of Experiment 3, however, is that the participants had to receive some substantial training to enable them to use the subordinate-level name correctly, just as in the corresponding study by Vitkovitch and Tyrrell (1999). To make sure that our findings are not restricted to this specific situation, the following experiments were conducted in an attempt to replicate these results with a different set of materials. The preferred names of the pictures used in Experiments 1-3 were located at the basic level of abstraction, as was established in the pretest. In Experiments 4 and 5, a different set of pictures was used with the preferred picture names located at the subordinate level of abstraction. Whereas black-and-white line drawings were used in the first three experiments, photorealistic stimuli were used in the following experiments to enhance naming on the subordinate level. If the findings of the first three experiments generalize to materials with name preferences at the subordinate level, a similar pattern should be obtained with these new materials. Since the subordinate-level names were preferred for the pictures used in these experiments, no extensive training (on either subordinate-level or basic-level naming) was necessary.

\section{EXPERIMENT 4}

In Experiment 4, we investigated effects of subordinatelevel name distractors (e.g., shark) during basic-level naming (e.g., fish) mirroring the procedure of Experiment 1 . The preferred naming level for the pictures used in this experiment was, however, located at the subordinate level of abstraction.

\footnotetext{
Method

Participants. Thirty-two participants were tested in this experiment.

Materials. We used photo-realistic pictures of simple objects, which contained sufficient detail that they could be named at either the basic level (e.g., fish) or the subordinate level (e.g., shark). For the 20 items used, normed name preference was located at the subordinate level, according to the results of a free-naming pretest. In this pretest, 90 line drawings of objects from 19 basic-level categories were presented to an independent sample of 27 participants. The number of subordinate-level exemplars belonging to a basic-level category varied from 2 to 17 . The participants were instructed to name the pictures with the first appropriate name that came to mind in response to each picture. The experimental items were selected according to the following general criteria: (1) dominance of the intended subordinate-level name - that is, the participants provided the subordinate-level name in the majority of cases $(M=89.3 \%$, $S D=8.3 \%$; range, $72.7 \%-100.0 \%$ ); (2) consistency of usage of the intended basic- and subordinate-level names - that is, the participants provided the intended basic-level or subordinate-level name in the majority of cases $(M=93.9 \%, S D=7.7 \%$; range, $75.7 \%-$ $100.0 \%$; (3) absence of initial phonological overlap between basiclevel and subordinate-level names; and (4) restriction to items with monomorphemic subordinate-level and basic-level names. The 20 selected objects belonged to 10 basic-level categories, with 2 objects from each category. For each object, two distractors were chosen in the same way as described for Experiment 2. See Appendix C for a complete list of the experimental materials.
}

Pictures were sized to fill an imaginary square of about $10 \times$ $10 \mathrm{~cm}(226 \times 226$ pixels $)$. The acoustic distractor words were spoken by a female native speaker of German. Subordinate-level name distractors varied in duration from 424 to $635 \mathrm{msec}$, with an average of $566 \mathrm{msec}(S D=71 \mathrm{msec})$. Phonologically related distractors varied in duration from 471 to $715 \mathrm{msec}$, with an average of $611 \mathrm{msec}(S D=90 \mathrm{msec})$. An additional set of eight objects with appropriate distractors was selected, to be used in warm-up trials.

Design. The design was identical to that used in Experiments 1 and 3, with the following exceptions. Because of a programming error, instead of SOA $0 \mathrm{msec}$, SOA $80 \mathrm{msec}$ was used. Each experimental block began with eight warm-up items.

Procedure. The participants named the target picture as quickly as possible with the (nonpreferred) basic-level name. The procedure was identical to that used in Experiment 1, with the following exceptions. The visual stimuli were presented as color photographs with their backgrounds removed by a masking tool. Auditory distractors were presented at SOAs of 80,100, 200, and $300 \mathrm{msec}$.

\section{Results and Discussion}

The raw data were treated as in the previous experiments. Four hundred ninety-one observations $(4.8 \%)$ were marked as erroneous, and 180 observations $(1.8 \%)$ were marked as outliers. These data points were discarded from the RT analyses.

Table 4 displays mean RTs and error rates by SOA and distractor type.

Effects of subordinate-level name distractors. Naming latencies and error rates decreased from the short SOAs to the long SOAs, yielding significant SOA effects [for RTs, $F_{1}(3,93)=35.94, M S_{\mathrm{e}}=1,786.23, p<$ .001 and $F_{2}(3,57)=116.45, M S_{\mathrm{e}}=340.84, p<.001$; for error rates, $F_{1}(3,93)=4.59, M S_{\mathrm{e}}=1.15, p<.01$ and $\left.F_{2}(3,57)=5.00, M S_{\mathrm{e}}=1.69, p<.05\right]$. Relatedness was also significant for naming latencies $\left[F_{1}(1,31)=34.19\right.$, $M S_{\mathrm{e}}=786.02, p<.001 ; F_{2}(1,19)=13.39, M S_{\mathrm{e}}=$ $1,427.69, p<.01]$ and error rates $\left[F_{1}(1,31)=9.69, M S_{\mathrm{e}}=\right.$ $\left.1.01, p<.01 ; F_{2}(1,19)=7.26, M S_{\mathrm{e}}=2.15, p<.05\right]$, reflecting longer and less accurate naming responses with distractors denoting an object's subordinate-level name than with unrelated distractors. Relatedness interacted with SOA in the analysis of naming latencies $\left[F_{1}(3,93)=\right.$ $16.08, M S_{\mathrm{e}}=536.50, p<.001 ; F_{2}(3,57)=13.25, M S_{\mathrm{e}}=$ $437.52, p<.001]$ and error rates $\left[F_{1}(3,93)=3.09\right.$, $M S_{\mathrm{e}}=1.27, p<.05 ; F_{2}(3,57)=4.45, M S_{\mathrm{e}}=1.41, p<$ $.01]$, reflecting the fact that the interfering effect of related distractors was confined to SOAs $80 \mathrm{msec}$ and $100 \mathrm{msec}$ for RTs [for SOA $80 \mathrm{msec}, t_{1}(31)=7.22, p<$ .001 and $t_{2}(19)=4.22, p<.001$; for SOA $100 \mathrm{msec}$, $t_{1}(31)=5.43, p<.001$ and $t_{2}(19)=4.61, p<.001$; all other $t \mathrm{~s}<1$ ] and to SOA $80 \mathrm{msec}$ for error rates [for SOA $80 \mathrm{msec}, t_{1}(31)=3.14, p<.01$ and $t_{2}(19)=4.42$, $p<.001$; for SOA $100 \mathrm{msec}, t_{1}(31)=1.23, p>.20$ and $t_{2}(19)=1.64, p>.10$; for SOA $200 \mathrm{msec}, t_{1}(31)=1.00$, $p>.30$ and $t_{2}(19)=.80, p>.40$; all other $\left.t \mathrm{~s}<1\right]$.

Effects of phonologically related distractors. Naming latencies decreased from short SOAs to long SOAs, yielding a significant $\mathrm{SOA}$ effect $\left[F_{1}(3,93)=7.56, M S_{\mathrm{e}}=\right.$ $1,198.14, p<.001 ; F_{2}(3,57)=15.37, M S_{\mathrm{e}}=347.20, p<$ .001]. Relatedness was significant for naming latencies $\left[F_{1}(1,31)=219.21, M S_{\mathrm{e}}=543.96, p<.001 ; F_{2}(1,19)=\right.$ 
Table 4

Experiment 4: Mean Reaction Times (in Milliseconds) and Error Rates (\%Error) by SOA and Distractor Type

\begin{tabular}{|c|c|c|c|c|c|c|c|c|}
\hline \multirow[b]{3}{*}{ Distractor } & \multicolumn{8}{|c|}{$\mathrm{SOA}(\mathrm{msec})$} \\
\hline & \multicolumn{2}{|c|}{80} & \multicolumn{2}{|c|}{100} & \multicolumn{2}{|c|}{200} & \multicolumn{2}{|c|}{300} \\
\hline & $M$ & $\%$ Error & $M$ & $\%$ Error & $M$ & $\%$ Error & $M$ & $\%$ Error \\
\hline Sub & 648 & 9.2 & 647 & 7.3 & 582 & 6.1 & 565 & 3.1 \\
\hline Unr & 606 & 3.9 & 608 & 5.5 & 579 & 4.8 & 567 & 3.8 \\
\hline Difference & $+42^{* * * / * * *}$ & $5.3^{* * / * * *}$ & $+39^{* * * / * * *}$ & +1.8 & +3 & 1.3 & -2 & -0.7 \\
\hline Bas-Rel & 545 & 3.9 & 546 & 2.5 & 546 & 3.4 & 549 & 2.3 \\
\hline Bas-Unr & 610 & 4.8 & 610 & 4.2 & 578 & 4.2 & 560 & 3.4 \\
\hline Difference & $-65^{* * * / * * *}$ & -0.9 & $-64^{* * * / * * *}$ & $-1.7^{* / \mathrm{n} . \mathrm{s} .}$ & $-32^{* * * / * * *}$ & -0.8 & $-11^{* * / *}$ & -1.1 \\
\hline
\end{tabular}

Note-SOA, stimulus onset asynchrony; Sub, subordinate-level name; Unr, unrelated to subordinate-level name; Bas-Rel, phonologically related to the basic-level target name; Bas-Unr, phonologically unrelated to the basic-level target name. Positive difference scores reflect interference, and negative difference scores reflect facilitation. The significance of these scores is indicated by superscripts, in which results from the $t$ tests by participant precede results from the $t$ tests by item. ${ }^{*} p<.05$. ${ }^{* *} p<.01 . \quad{ }^{* * *} p<.001$.

$\left.60.21, M S_{\mathrm{e}}=1,276.05, p<.001\right]$ and marginally significant for error rates $\left[F_{1}(1,31)=3.66, M S_{\mathrm{e}}=0.90, p=\right.$ $\left..065 ; F_{2}(1,19)=3.13, M S_{\mathrm{e}}=1.68, p=.093\right]$, reflecting faster and more accurate responses with phonologically related distractors than with unrelated distractors. In the analysis of naming latencies, relatedness interacted with SOA $\left[F_{1}(3,93)=23.82, M S_{\mathrm{e}}=459.03, p<.001\right.$; $\left.F_{2}(3,57)=19.57, M S_{\mathrm{e}}=338.58, p<.001\right]$, reflecting the fact that more facilitation was obtained at shorter than at longer SOAs [for SOA $80 \mathrm{msec}, t_{1}(31)=-9.89, p<$ .001 and $t_{2}(19)=-7.10, p<.001$; for SOA $100 \mathrm{msec}$, $t_{1}(31)=-11.52, p<.001$ and $t_{2}(19)=-7.15, p<$ .001 ; for SOA $200 \mathrm{msec}, t_{1}(31)=-5.84, p<.001$ and $t_{2}(19)=-5.45, p<.001$; for SOA $300 \mathrm{msec}, t_{1}(31)=$ $-2.87, p<.01$ and $\left.t_{2}(19)=-2.37, p<.05\right]$.

Experiment 4 showed again that distractors denoting an object's subordinate-level name interfere with basic-level naming more than unrelated distractors do. This replicates the findings of Experiments 1 and 2 with a different set of materials. Distractors denoting subordinate-level names of target pictures to be named with their (nonpreferred) basic-level names likewise yielded a semantic between-levels interference effect. The following experiment tested for the semantic between-levels effect during subordinate-level naming.

\section{EXPERIMENT 5}

In Experiment 5, we tested subordinate-level naming in the presence of distractors denoting the basic-level names of objects. The subordinate level was the preferred naming level for the pictures used in this experiment.

\section{Method}

Participants. Thirty-two participants were tested.

Materials. The picture stimuli were identical to those used in Experiment 4 . For each picture, two new distractors were selected. The first distractor denoted the object's basic-level name. These basiclevel name distractors varied in duration from 482 to $864 \mathrm{msec}$, with an average of $616 \mathrm{msec}(S D=95 \mathrm{msec})$. The second distractor was phonologically related to the subordinate-level target word. As before, these distractors shared, at a minimum, the initial vowel or consonant-vowel segment with the subordinate-level target name. They varied in duration from 500 to $755 \mathrm{msec}$, with an average of $620 \mathrm{msec}(S D=73 \mathrm{msec})$. See Appendix D for a complete list of the experimental materials.

Design. The design was identical to that used in Experiment 4.

Procedure. The procedure was identical to that used in Experiment 4 , with the following exceptions. In the picture booklet, the basic-level names were replaced by the subordinate-level names, and the participants were instructed to name the target pictures as quickly as possible using these names.

\section{Results and Discussion}

The raw data were treated as in the previous experiments. Five hundred forty-four observations (5.3\%) were marked as erroneous, and 174 observations (1.7\%) were marked as outliers. These data points were discarded from the RT analyses.

Table 5 displays mean RTs and error rates by SOA and distractor type.

Effects of basic-level name distractors. Naming latencies decreased from short SOAs to long SOAs, yielding a significant SOA effect $\left[F_{1}(3,93)=17.57, M S_{\mathrm{e}}=\right.$ $1,322.34, p<.001 ; F_{2}(3,57)=39.56, M S_{\mathrm{e}}=355.02, p<$ $.001]$. Relatedness was only marginally significant in the subject RT analysis $\left[F_{1}(1,31)=3.74, M S_{\mathrm{e}}=471.33, p=\right.$ $\left..062 ; F_{2}(1,19)=1.63, M S_{\mathrm{e}}=803.24, p>.20\right]$, reflecting a tendency for longer naming responses with distractors denoting an object's basic-level name in comparison with unrelated distractors. Relatedness and SOA interacted in the analysis of naming latencies $\left[F_{1}(3,93)=3.94, M S_{\mathrm{e}}=\right.$ $568.88, p<.05 ; F_{2}(3,57)=5.26, M S_{\mathrm{e}}=331.55, p<$ $.01] . t$ tests revealed that longer naming latencies for basiclevel distractors were observed only at SOAs $80 \mathrm{msec}$ and $100 \mathrm{msec}$ [for SOA $80 \mathrm{msec}, t_{1}(31)=2.55, p<.05$ and $t_{2}(19)=2.14, p<.05$; for SOA $100 \mathrm{msec}, t_{1}(31)=3.14$, $p<.01$ and $t_{2}(19)=2.22, p<.05$; for SOA $200 \mathrm{msec}$, $t_{1}(31)=-1.43, p>.10$ and $t_{2}(19)=-2.10, p=.05$; all other $t \mathrm{~s}<1]$. The analysis of error rates revealed no significant effects. 
Table 5

Experiment 5: Mean Reaction Times (in Milliseconds) and Error Rates (\%Error) by SOA and Distractor Type

\begin{tabular}{|c|c|c|c|c|c|c|c|c|}
\hline \multirow[b]{3}{*}{ Distractor } & \multicolumn{8}{|c|}{$\mathrm{SOA}(\mathrm{msec})$} \\
\hline & \multicolumn{2}{|c|}{80} & \multicolumn{2}{|c|}{100} & \multicolumn{2}{|c|}{200} & \multicolumn{2}{|c|}{300} \\
\hline & $M$ & $\%$ Error & $M$ & $\%$ Error & $M$ & $\%$ Error & $M$ & $\%$ Error \\
\hline Bas & 645 & 7.2 & 645 & 7.0 & 610 & 4.5 & 598 & 5.9 \\
\hline Unr & 630 & 6.4 & 629 & 4.5 & 619 & 5.9 & 598 & 5.2 \\
\hline Difference & $+15^{* / *}$ & +0.8 & $+16^{* * / *}$ & $+2.5^{\dagger / \mathrm{n} . \mathrm{s}}$ & -9 & -1.4 & 0 & +0.7 \\
\hline Sub-Rel & 566 & 2.5 & 565 & 3.1 & 570 & 3.4 & 581 & 5.9 \\
\hline Sub-Unr & 657 & 5.9 & 639 & 7.0 & 614 & 5.0 & 597 & 4.4 \\
\hline Difference & $-91^{* * * / * * *}$ & $-3.4^{* * / * *}$ & $-74^{* * * / * * *}$ & $-3.9^{* * * / * *}$ & $-44^{* * * / * * *}$ & -1.6 & $-16^{* * / *}$ & +1.5 \\
\hline
\end{tabular}

Note-The preferred subordinate-level name is the target word. For an explanation of abbreviations and scores, see the note to Table 3. ${ }^{*} p<.05 .{ }^{* *} p<.01 .{ }^{* * *} p<.001 . \quad{ }^{\dagger} p<.1$.

Effects of phonologically related distractors. Naming latencies decreased from short SOAs to long SOAs, yielding a significant $\mathrm{SOA}$ effect $\left[F_{1}(3,93)=4.43\right.$, $M S_{\mathrm{e}}=1,573.84, p<.01 ; F_{2}(3,57)=11.77, M S_{\mathrm{e}}=$ $347.95, p<.001]$. Relatedness was significant for naming latencies $\left[F_{1}(1,31)=279.98, M S_{\mathrm{e}}=726.49, p<\right.$ $\left..001 ; F_{2}(1,19)=94.55, M S_{\mathrm{e}}=1,384.85, p<.001\right]$ and error rates $\left[F_{1}(1,31)=15.07, M S_{\mathrm{e}}=0.57, p<.01\right.$; $\left.F_{2}(1,19)=4.90, M S_{\mathrm{e}}=2.82, p<.05\right]$, reflecting faster and more accurate responses with phonologically related distractors in comparison with unrelated distractors. In the analyses of RTs and error rates, relatedness interacted with SOA [for RTs, $F_{1}(3,93)=37.69, M S_{\mathrm{e}}=470.91$, $p<.001$ and $F_{2}(3,57)=34.77, M S_{\mathrm{e}}=331.16, p<.001$; for error rates, $F_{1}(3,93)=4.68, M S_{\mathrm{e}}=0.84, p<.01$ and $\left.F_{2}(3,57)=4.17, M S_{\mathrm{e}}=1.51, p<.05\right] . t$ tests revealed that more facilitation was obtained for short than for long SOAs [for SOA $80 \mathrm{msec}, t_{1}(31)=-14.39, p<.001$ and $t_{2}(19)=-9.75, p<.001$; for SOA $100 \mathrm{msec}, t_{1}(31)=$ $-10.75, p<.001$ and $t_{2}(19)=-9.25, p<.001$; for SOA $200 \mathrm{msec}, t_{1}(31)=-8.58, p<.001$ and $t_{2}(19)=-7.33$, $p<.001$; for SOA $300 \mathrm{msec}, t_{1}(31)=-3.60, p<.01$ and $\left.t_{2}(19)=-2.41, p<.05\right]$ and that related distractors led to fewer errors in comparison with unrelated distractors only for SOAs $80 \mathrm{msec}$ and $100 \mathrm{msec}$ [for SOA $80 \mathrm{msec}$, $t_{1}(31)=-2.78, p<.01$ and $t_{2}(19)=-3.24, p=.01$; for SOA $100 \mathrm{msec}, t_{1}(31)=-4.02, p<.001$ and $t_{2}(19)=$ $-3.21, p<.01$; for SOA $200 \mathrm{msec}, t_{1}(31)=-1.47, p>$ .10 and $t_{2}(19)=-1.17, p>.20$; for SOA $300 \mathrm{msec}$, $t_{1}(31)=1.41, p>.10$ and $\left.t_{2}(19)=.93, p>.30\right]$.

Experiment 5 showed again that distractors denoting an object's basic-level name interfere with subordinatelevel naming more than unrelated distractors do. Thus, the notion that basic-level names become lexically activated during subordinate-level naming and that these basiclevel names compete for selection with the subordinatelevel target word is further supported by this finding.

\section{GENERAL DISCUSSION}

Five picture-word experiments showed semantic between-levels interference. Experiments 1, 2, and 4 showed that basic-level picture naming (e.g., fish) was delayed by a distractor denoting a subordinate-level name of the depicted object (e.g., carp/shark) relative to an unrelated distractor (e.g., oak). Similarly, Experiments 3 and 5 showed that subordinate-level picture naming (e.g., carp/shark) was delayed by a distractor denoting the depicted object's basic-level name (e.g., fish) relative to an unrelated distractor (e.g., tree). The semantic betweenlevels interference effect was obtained with two different sets of materials. In Experiments 1-3, black-and-white line drawings were used with their preferred level of naming at the basic level of abstraction. In Experiments 4 and 5 , photo-realistic stimuli were used with their preferred naming level at the subordinate level of abstraction.

In addition, facilitation from distractors phonologically related to the target name was obtained in all the experiments. As was mentioned earlier, the phonological distractor conditions were included to demonstrate an experiment's sensitivity for the case in which no semantic between-levels effect would be obtained. Since this was not the case, we will not elaborate on the phonological facilitation effect in the remainder of this article.

The results for the semantic between-levels distractor conditions resemble the well-established semantic withinlevel interference effect. They took the same direction (interference rather than facilitation). They were confined to SOAs of 0,80 , and $100 \mathrm{msec}$, showing a time course comparable to that of within-level interference effects (confined to SOAs around $0 \mathrm{msec} \pm 150 \mathrm{msec}$; see, e.g., Damian \& Martin, 1999; Roelofs, 1992; Schriefers et al., 1990). The only exception with respect to the observed time course occurred in Experiment 3. Here, the participants were instructed to use the nonpreferred subordinatelevel name to name target objects whose preferred naming level is the basic level of abstraction. In this experiment, the effect for subordinate-level naming extended to longer positive SOAs (200 msec and, descriptively, $300 \mathrm{msec}$ ). We will return to this issue shortly.

Together, the data from our experiments suggest that lexical competition among semantically related words is restricted neither to basic-level naming nor to lexical representations stemming from the same level of abstraction. Rather, it appears that regardless of whether the object is being named at the basic level or the subordinate level, 
semantically related words from both levels become activated and compete for selection with the target. The same pattern of results emerges if the preferred naming level of the visual stimuli lies on the basic (Experiments 1-3) or the subordinate (Experiments 4 and 5) level of abstraction.

As was just mentioned, the time course of the semantic interference effect during subordinate-level naming in Experiment 3 extended to longer positive SOAs than it did during basic-level naming in Experiments 1 and 2. This difference can be explained when one considers that overall naming latencies in Experiment 3 were some 150-200 msec longer in comparison with those in Experiments 1 and 2, in which the same target objects were named with their basic-level names. These longer naming latencies might be explained by an extended conceptual preparation stage, needed for extracting and coding additional stimulus attributes necessary for subordinate-level identification. According to the model of Levelt et al. (1999), a lemma representation will be activated when the corresponding concept has become activated. Hence, any extension of the conceptual preparation phase should also expand the time window in which semantically related distractors can interfere with the lemma-processing stage. This fact might also account for the slightly different time course of the semantic interference effect in Experiment 3, in comparison with those of Experiments 1 and 2. In line with this interpretation, the effects of phonologically related distractors were also found to fade out later in Experiment 3 than in Experiments 1 and 2. Notice that for Experiments 4 and 5 the difference between the mean naming latencies is no longer substantial. This probably reflects the fact that the subordinate-level names are the preferred names for the target objects used in those experiments. The relevant visual information necessary to retrieve the subordinate-level name is probably much easier to retrieve from this kind of stimuli. Therefore, a substantially longer conceptual preparation phase is not necessary to retrieve the subordinate-level names in Experiment 5.

As a whole, the results of these five experiments show a robust and symmetrical semantic between-levels interference effect. As Vitkovitch and Tyrrell (1999) pointed out, between-levels interference is what one would expect when considering current models of word production. In order to incorporate the between-levels facilitation effects reported by Vitkovitch and Tyrrell and by Roelofs (1992), additional assumptions are required. However, the present data show that such changes might not be necessary, since reliable between-levels interference can be obtained. Of course, the results reported here raise the question of why the results diverge. At least the following factors should be considered: (1) distractor modality, (2) amount of visual information present in pictorial stimuli, (3) response set size, (4) response repetition (learning phases, practice phases, etc.), and (5) picture set size. A first possibility concerns the modality of distractor presentation. In the present study auditory distractors were used, whereas Vitkovitch and Tyrrell used visual distractors. It seems very unlikely, however, that this difference can account for the contradictory results. For example, Damian and Martin (1999) systematically compared the effects of withinlevel distractors presented visually and auditorily in the picture-word paradigm and did not find any indication of qualitative differences between modalities. Semantic interference was obtained with both auditorily and visually presented distractors. Of course, strictly speaking, the results reported by Damian and Martin do not necessarily rule out the possibility that modality of distractor presentation has an effect for between-levels distractors. However, such a modulation of effects of distractor modality by level of abstraction still appears highly unlikely, in particular since all relevant distractor effects in the picture-word task (e.g., phonological/orthographic facilitation, within-level semantic interference, gender interference) have until now proven to be independent of distractor modality. In a recent study, Zwitserlood, Bölte, and Dohmes (2004) reported semantic between-levels interference obtained with visually presented distractor words (basic-level target [e.g., dog], subordinate-level distractor [e.g., dalmatian]). However, in their study the pictures that were used did not contain sufficient detail to allow identification at the subordinate level of abstraction. So the possibility remains that the direction and/or size of the effect is influenced somewhat by the combination of visual distractors and pictorial stimuli that contain more detailed visual information than the standard basiclevel pictures. Note, however, that this factor alone does not suffice to explain the reported between-levels facilitation effect, since Vitkovitch and Tyrrell reported semantic inhibition for within-level distractors (in basic-level and subordinate-level naming) using the same picture set as in their between-levels experiment.

A second account of the divergent findings relates to the possibility that participants in the Vitkovitch and Tyrrell (1999) study might have used the basic-level distractors as retrieval cues for the subordinate target names. In their study, the basic-level names were, according to their norm data, the preferred naming responses and hence should have been readily available to the participants when they viewed a picture. In fact, participants had to be trained to use the correct subordinate-level names in the experiment (and still performed about $150 \mathrm{msec}$ slower than in the basic-level naming condition). Possibly, participants in the Vitkovitch and Tyrrell study established associations between their preferred (basic-level) picture name and the required (subordinate-level) response during this training. Since only 10 pictures and only one exemplar from each basic-level category were included, the basic-level distractors presented during the experiment could have served as retrieval cues facilitating selection of the nonpreferred name. ${ }^{4}$ Note that this account is not in conflict with semantic within-level interference effects, as observed by Vitkovitch and Tyrrell (Experiment 1). In this case, the semantically related subordinate-level distractor (e.g., adder when the target is cobra), unlike the semantically related basic-level name (e.g., snake), cannot act as an effective retrieval cue. This is because this subordinate- 
level distractor is not identical to the lexical item that comes to participants' minds when they viewed the picture stimulus. By contrast, in our study the impact of such extralexical processes can be assumed to be much weaker. Although our participants also were trained to use nonpreferred names during subordinate-level naming (Experiment 3), there were more than twice as many items, making it much more difficult to use the basic-level distractors as retrieval cues for the subordinate-level target response. Furthermore, there was no one-to-one mapping between (related) basic-level distractor and subordinate-level target response. This was the case because two exemplars from each basic-level category were included in the experiment. Thus, the amount of materials used and the absence of one-to-one mapping between (related) distractor and target rendered the distractors in our experiment less valid retrieval cues. However, this explanation by itself again does not suffice to explain the differences, as was shown in two control experiments we performed. In these experiments, we had participants name just one exemplar of each basic-level category with its subordinate-level name, mirroring the corresponding design feature of Vitkovitch and Tyrrell. In one of these experiments (A), the same materials employed in Experiments 1-3 were used, with one subexperiment (A1) testing only one member of each of the 12 categories and the other subexperiment (A2) testing the other member of the corresponding category. In the other experiment (B), the materials used in Experiments 4 and 5 were tested in the same way. Four SOAs were used $(-200,-100,0$, and $100 \mathrm{msec})$. We included negative SOAs in these control experiments because Roelofs (1992) reported between-levels facilitation at the SOA of $-100 \mathrm{msec}$. In Experiment $A$, a significant 17-msec interference effect was obtained $\left[F_{1}(1,31)=\right.$ $20.80, M S_{\mathrm{e}}=917.42, p<.001 ; F_{2}(1,23)=9.17, M S_{\mathrm{e}}=$ $1,502.01, p<.01]$. The interaction between SOA and relatedness was also significant $\left[F_{1}(3,93)=3.60, M S_{\mathrm{e}}=\right.$ $686.27, p<.05 ; F_{2}(3,69)=2.83, M S_{\mathrm{e}}=642.89, p<$ $.05]$, reflecting the fact that the interference effect was carried mainly by SOAs of 0 and $100 \mathrm{msec}$ (the interference effect was $10 \mathrm{msec}$ for SOA $-200 \mathrm{msec}, 4 \mathrm{msec}$ for $\mathrm{SOA}-100 \mathrm{msec}, 25 \mathrm{msec}$ for SOA $0 \mathrm{msec}$, and $30 \mathrm{msec}$ for SOA $100 \mathrm{msec}$ ). No significant effects of error rates were obtained (all $p \mathrm{~s}>$.14). In Experiment $\mathrm{B}$, an 11-msec interference effect proved to be significant as well $\left[F_{1}(1,31)=5.60, M S_{\mathrm{e}}=1,331.65, p<.05 ; F_{2}(1,19)=\right.$ $\left.9.96, M S_{\mathrm{e}}=532.43, p<.01\right]$. Neither SOA nor the interaction between SOA and relatedness reached significance in this experiment (all $p \mathrm{~s}>.31$ ), and no significant effects of error rates were obtained (all $p s>.25$ ).

In light of these results, the explanation given above cannot explain by itself how the semantic facilitation effect comes about.

Recently, Costa et al. (2003) reported that during basiclevel naming, semantically unrelated basic-level distractors interfered more than semantically unrelated superordinatelevel distractors with the naming response. Participants instructed to categorize the same pictures, however, showed a reverse pattern: Basic-level distractors interfered less than superordinate-level distractors during picture categorization. The authors propose an explanation for their finding that is akin to Roelofs's (1992) response set criterion. Instead of allowing competition only between members of the previously established response set (cf. Roelofs, 1992), Costa et al. assumed that only words from the same level of abstraction as the target word compete for selection. A semantically related distractor word from a different level of abstraction is not regarded as a possible response, so no competition is predicted. Because of the spread of activation, this between-levels distractor word is thought to activate the target word, thereby causing the reported facilitation effect. This assumption would predict facilitative between-levels effects irrespective of the levels of abstractions used. However, the opposite effect - namely, semantic interference-was observed in the five experiments reported here. It should be noted, however, that Costa et al.'s study is concerned with the basic level and the superordinate level. Thus, one could hypothesize that superordinate-level categories (used to refer to groups of objects) are different from the more specific categories (e.g., basic-level and subordinate-level names, used to refer to single objects) in that they do not enter into lexical competition. From this point of view, the results of Costa et al. could be considered as further evidence of a special status of superordinate-level names.

In conclusion, current models of picture naming predict lexical competition within levels of abstraction and between the basic level and the subordinate level. However, the only two studies concerned with such between-levels effects during picture naming found in the literature reported semantic facilitation instead of semantic interference. These results would call for some adjustment of current models of speech production that restricts lexical competition to that within a given level of abstraction. However, the experiments reported in this article show that semantic effects between the basic level and the subordinate level can be inhibitory. This finding suggests that for the basic and the subordinate levels, lexical competition is not confined to a given level. Furthermore, the present results show that between-levels interference can be very robust, since it was obtained irrespective of whether one or two exemplars of a basic category are used in an experiment (Experiments 1 and 2 vs. Experiment 3 and the control studies just mentioned) and irrespective of whether name preference is on the basic level or the subordinate level (Experiments 1-3 vs. Experiments 4 and 5). Obviously, the present results also invite further research into the factors that lead to the observation of between-levels facilitation effects (Roelofs, 1992; Vitkovitch \& Tyrrell, 1999) versus the between-levels interference effects observed in the present experiments. Potential factors that should be taken into account include (but are not limited to) distractor modality, response set size, picture set size, number of repetitions, and specific visual information of pictures. It seems, however, that none of these factors alone suffices to explain the occurrence of semantic facilitation effects.

Finally, the emerging picture raises the questions of whether and how picture categorization at the superor- 
dinate level differs from picture naming at the basic level and the subordinate level.

\section{REFERENCES}

Bloem, I., \& La HeIJ, W. (2003). Semantic facilitation and semantic interference in word translation: Implications for models of lexical access in language production. Journal of Memory \& Language, 48, $468-488$.

Caramazza, A., \& Costa, A. (2000). The semantic interference effect in the picture-word interference paradigm: Does the response set matter? Cognition, 75, B51-B64.

Clark, H. (1973). The language-as-fixed-effect fallacy: A critique of language statistics in psychological research. Journal of Verbal Learning \& Verbal Behavior, 12, 335-359.

Clark, J. M., \& Johnson, C. J. (1994). Retrieval mechanisms in the development of instance and superordinate naming of pictures. Journal of Experimental Child Psychology, 57, 295-326.

Costa, A., Mahon, B., Savova, V., \& Caramazza, A. (2003). Level of categorization effect: A novel effect in the picture-word interference paradigm. Language \& Cognitive Processes, 18, 205-233.

DAMIAN, M. F., \& BowERs, J. S. (2003). Locus of semantic interference in picture-word interference tasks. Psychonomic Bulletin \& Review, 10, 111-117.

Damian, M. F., \& Martin, R. C. (1999). Semantic and phonological codes interact in single word production. Journal of Experimental Psychology: Learning, Memory, \& Cognition, 25, 345-361.

DelL, G. S. (1986). A spreading-activation theory of retrieval in sentence production. Psychological Review, 93, 283-321.

Glaser, W. R., \& Düngelhoff, F. J. (1984). The time course of picture-word interference. Journal of Experimental Psychology: Human Perception \& Performance, 10, 640-654.

HumphreYs, G. W., \& FordE, E. M. E. (2001). Hierarchies, similarity, and interactivity in object recognition: "Category-specific" neuropsychological deficits. Behavioral \& Brain Sciences, 24, 453-509.

Humphreys, G. W., Lamote, C., \& Lloyd-Jones, T. J. (1995). An interactive activation approach to object processing: Effects of structural similarity, name frequency, and task in normality and pathology. Memory, 3, 535-586.

Humphreys, G. W., RidDoch, M. J., \& Quinlan, P. T. (1988). Cascade processes in picture identification. Cognitive Neuropsychology, 5, 67-103.

IRWIN, D. I., \& LUPKER, S. J. (1983). Semantic priming of pictures and words: A levels of processing approach. Journal of Verbal Learning \& Verbal Behavior, 22, 45-60.

JescheniaK, J. D., \& Levelt, J. M. (1994). Word frequency effects in speech production: Retrieval of syntactic information and of phonological form. Journal of Experimental Psychology: Learning, Memory, \& Cognition, 20, 824-843.

Jescheniak, J. D., Schriefers, H., \& Hantsch, A. (2001). Semantic and phonological activation in noun and pronoun production. Journal of Experimental Psychology: Learning, Memory, \& Cognition, 27, 1058-1078.

Jescheniak, J. D., Schriefers, H., \& Hantsch, A. (2003). Utterance format affects phonological priming in the picture-word task: Implications for models of phonological encoding in speech production. Journal of Experimental Psychology: Human Perception \& Performance, 29, 441-454.

Johnson, C. J., Paivio, A., \& Clark, J. M. (1996). Cognitive components of picture naming. Psychological Bulletin, 120, 113-139.

Joliceur, P., Gluck, M. A., \& Kosslyn, S. M. (1984). Picture and names: Making the connection. Cognitive Psychology, 16, 243-275.

Kuipers, J. R., \& La HeIJ, W. (2004, September). When you call a dog an animal: Context effects in categorization tasks. Paper presented at the International Workshop on Language Production, Marseille, France.

Levelt, W. J. M., Roelofs, A., \& Meyer, A. S. (1999). A theory of lexical access in speech production. Behavioral \& Brain Sciences, 22, 1-75.
Levelt, W. J. M., Schriefers, H., Vorberg, D., Meyer, A. S., PechMANN, T., \& HAVINGA, J. (1991). The time course of lexical access in speech production: A study of picture naming. Psychological Review, 98, 122-142.

Lin, E. L., Murphy, G. L., \& Shoben, E. J. (1997). The effects of prior processing episodes on basic-level superiority. Quarterly Journal of Experimental Psychology, 50A, 25-48.

LUPKER, S. J. (1979). The semantic nature of response competition in the picture-word interference task. Memory \& Cognition, 7, 485-495.

LUPKER, S. J., \& KATZ, A. N. (1981). Input, decision, and response factors in picture-word interference. Journal of Experimental Psychology: Human Learning \& Memory, 7, 269-282.

MaCLEOD, C. M. (1991). Half a century of research on the Stroop effect: An integrative review. Psychological Bulletin, 109, 163-203.

Meyer, A. S., \& Schriefers, H. (1991). Phonological facilitation in picture-word interference experiments: Effects of stimulus onset asynchrony and types of interfering stimuli. Journal of Experimental Psychology: Learning, Memory, \& Cognition, 17, 1146-1160.

MuRPHY, G. L., \& WISNIEWSKI, E. J. (1989). Categorizing objects in isolation and in scenes: What a superordinate is good for. Journal of Experimental Psychology: Learning, Memory, \& Cognition, 15, 572-586.

RoELOFs, A. (1992). A spreading-activation theory of lemma retrieval in speaking. Cognition, 42, 107-142.

RoElofs, A. (1993). Testing a non-decompositional theory of lemma retrieval in speaking: Retrieval of verbs. Cognition, 47, 59-87.

Roelofs, A. (2001). Set size and repetition matter: Comment on Caramazza and Costa (2000). Cognition, 80, 283-290.

Rosch, E., Mervis, C. B., Gray, W. D., Johnson, D. M., \& BoyesBraem, P. (1976). Basic objects in natural categories. Cognitive Psychology, 8, 382-439.

RosINSKI, R. R. (1977). Picture-word interference is semantically based. Child Development, 48, 643-647.

Schriefers, H., Meyer, A. S., \& Levelt, W. J. M. (1990). Exploring the time course of lexical access in production: Picture-word interference studies. Journal of Memory \& Language, 29, 86-102.

Smith, M. C., \& MageE, L. E. (1980). Tracing the time course of picture-word processing. Journal of Experimental Psychology: General, 109, 373-392.

Starreveld, P. A., \& La Heis, W. (1995). Semantic interference, orthographic facilitation, and their interaction in naming tasks. Journal of Experimental Psychology: Learning, Memory, \& Cognition, 21, 686-698.

UNDERWOOD, G. (1976). Semantic interference from unattended printed words. British Journal of Psychology, 67, 327-338.

Vigliocco, G., Vinson, D. P., Martin, R. C., \& Garrett, M. F. (1999). Is "count" and "mass" information available when the noun is not? An investigation of tip of the tongue states and anomia. Journal of Memory \& Language, 40, 534-558.

VitKovitch, M., \& TYRRELL, L. (1999). The effects of distractor words on naming pictures at the subordinate level. Quarterly Journal of Experimental Psychology, 52A, 905-926.

Wingfield, A. (1967). Perceptual and response hierarchies in object identification. Acta Psychologica, 26, 216-226.

Zwitserlood, P., Bölte, J., \& Dohmes, P. (2004, September). A differential impact of semantic and morphological distractors on picture naming. Poster presented at the 10th Annual Conference on Architectures and Mechanisms of Language Processing (AMLaP), Aix-enProvence, France.

\section{NOTES}

1. We refer to concepts by using capital letters and to lexical representations by using italics.

2. For a recent discussion of seemingly contradictory data (e.g., those of Lupker \& Katz, 1981), see Damian and Bowers (2003).

3 . The results from this questionnaire will not be reported in detail. Suffice it to say that analyses restricted to only those items for which the participants confirmed basic-level name preference after the experiment revealed essentially the same pattern as the analysis on all items. 
4. Actually, the authors suggest a similar explanation themselves: "Certainly, participants in the present experiment had the opportunity deliberately to inhibit basic level names before the experimental block began. Recall that they had a pre-experimental session where they agreed on subordinate names with the experimenter" (Vitkovitch \& Tyrrell, 1999, p. 921).

APPENDIXA

Basic-Level Target Names, Subordinate-Level Name Distractors, and

Distractors Phonologically Related and Phonologically Unrelated to the (Preferred) Basic-Level Target Names Used in Experiments 1 and 2

\begin{tabular}{|c|c|c|c|c|}
\hline \multirow{2}{*}{$\begin{array}{l}\text { Basic-Level } \\
\text { Target Name }\end{array}$} & \multirow[b]{2}{*}{ Sub } & \multirow[b]{2}{*}{ Sub-Unr } & \multicolumn{2}{|c|}{ Controls } \\
\hline & & & Bas-Rel & Bas-Unr \\
\hline Affe [primate] & $\begin{array}{l}\text { Schimpanse } \\
\text { [chimpanzee] }\end{array}$ & Porsche [Porsche] & Apfel [apple] & Foto [photo] \\
\hline Affe [primate] & Pavian [baboon] & Lilie [lily] & Apfel [apple] & Foto [photo] \\
\hline Auto [car] & Porsche [Porsche] & $\begin{array}{l}\text { Bungalow } \\
\text { [bungalow] }\end{array}$ & Aula [assembly hall] & Bluse [blouse] \\
\hline Auto [car] & Golf [Golf] & Spatz [sparrow] & Aula [assembly hall] & Bluse [blouse] \\
\hline Baum [tree] & Eiche [oak] & Viper [viper] & Bauch [belly] & Film [film] \\
\hline Baum [tree] & Pappel [poplar] & Fähre [ferry] & Bauch [belly] & Film [film] \\
\hline Blume [flower] & Veilchen [violet] & $\begin{array}{l}\text { Schimpanse } \\
\text { [chimpanzee] }\end{array}$ & Bluse [blouse] & Schlacke [slag] \\
\hline Blume [flower] & Lilie [lily] & Pavian [baboon] & Bluse [blouse] & Schlacke [slag] \\
\hline Fisch [fish] & Wels [catfish] & Morchel [morel] & Film [film] & Huld [grace] \\
\hline Fisch [fish] & Karpfen [carp] & Bongo [bongo] & Film [film] & Huld [grace] \\
\hline Haus [house] & $\begin{array}{l}\text { Bungalow } \\
\text { [bungalow] }\end{array}$ & Wels [catfish] & Haut [skin] & Tropfen [drop] \\
\hline Haus [house] & Villa [villa] & Pappel [poplar] & Haut [skin] & Tropfen [drop] \\
\hline Hund [dog] & Spitz [Pomeranian] & Veilchen [violet] & Huld [grace] & Apfel [apple] \\
\hline Hund [dog] & Mops [pug] & Villa [villa] & Huld [grace] & Apfel [apple] \\
\hline Pilz [mushroom] & Morchel [morel] & Jacht [yacht] & Pilger [pilgrim] & Haut [skin] \\
\hline Pilz [mushroom] & $\begin{array}{l}\text { Champignon } \\
\text { [mushroom] }\end{array}$ & Mops [pug] & Pilger [pilgrim] & Haut [skin] \\
\hline Schiff [ship] & Jacht [yacht] & Meise [titmouse] & Schicht [layer] & Bauch [belly] \\
\hline Schiff [ship] & Fähre [ferry] & Natter [adder] & Schicht [layer] & Bauch [belly] \\
\hline Schlange [snake] & Viper [viper] & Eiche [oak] & Schlacke [slag] & Aula [assembly hall] \\
\hline Schlange [snake] & Natter [adder] & Golf [Golf] & Schlacke [slag] & Aula [assembly hall] \\
\hline Trommel [drum] & Pauke [bass drum] & Spitz [Pomeranian] & Tropfen [drop] & Schicht [layer] \\
\hline Trommel [drum] & Bongo [bongo] & Karpfen [carp] & Tropfen [drop] & Schicht [layer] \\
\hline Vogel [bird] & Meise [titmouse] & Pauke [bass drum] & Foto [photo] & Pilger [pilgrim] \\
\hline Vogel [bird] & Spatz [sparrow] & $\begin{array}{l}\text { Champignon } \\
\text { [mushroom] }\end{array}$ & Foto [photo] & Pilger [pilgrim] \\
\hline
\end{tabular}

Note-Approximate English translations are given in brackets. Sub, subordinate-level name; Sub-Unr, unrelated to subordinate-level name; Bas-Rel, phonologically related to the basic-level target name; Bas-Unr, phonologically unrelated to the basic-level target name.

APPENDIX B

Subordinate-Level Target Names, Basic-Level Name Distractors, and

Distractors Phonologically Related and Phonologically Unrelated to the (Nonpreferred) Subordinate-Level Target Names Used in Experiment 3

\begin{tabular}{cllll}
\hline $\begin{array}{c}\text { Subordinate-Level } \\
\text { Target Name }\end{array}$ & \multicolumn{1}{c}{ Bas } & \multicolumn{1}{c}{ Bas-Unr } & \multicolumn{1}{c}{ Sub-Rel } & \multicolumn{1}{c}{ Sub-Unr } \\
\hline $\begin{array}{c}\text { Schimpanse } \\
\text { [chimpanzee] }\end{array}$ & Affe [primate] & Haus [house] & Schimmer [glimmer] & Visum [visa] \\
Pavian [baboon] & Affe [primate] & Haus [house] & Pavillion [pavilion] & Linie [line] \\
Porsche [Porsche] & Auto [car] & Schlange [snake] & Porree [leek] & Butter [butter] \\
Golf [Golf] & Auto [car] & Schlange [snake] & Gold [gold] & Spalt [slit] \\
Eiche [oak] & Baum [tree] & Schiff [ship] & Eile [hurry] & Porree [leek] \\
Pappel [poplar] & Baum [tree] & Schiff [ship] & Panne [mishap] & Gold [gold] \\
Veilchen [violet] & Blume [flower] & Affe [monkey] & Feile [file] & Pause [pause] \\
Lilie [lily] & Blume [flower] & Affe [monkey] & Linie [line] & Pavillion [pavilion]
\end{tabular}


APPENDIX B (Continued)

\begin{tabular}{|c|c|c|c|c|}
\hline Wels [catfish] & Fisch [fish] & Baum [tree] & Welt [world] & Meile [mile] \\
\hline Karpfen [carp] & Fisch [fish] & Baum [tree] & Karte [card] & Bombe [bomb] \\
\hline $\begin{array}{l}\text { Bungalow } \\
\text { [bungalow] }\end{array}$ & Haus [house] & Vogel [bird] & Butter [butter] & Welt [world] \\
\hline Villa [villa] & Haus [house] & Vogel [bird] & Wippe [seesaw] & Shampoo [shampoo] \\
\hline $\begin{array}{l}\text { Spitz } \\
\quad[\text { Pomeranian] }\end{array}$ & Hund [dog] & Auto [car] & Spind [locker] & Eile [hurry] \\
\hline Mops [pug] & Hund [dog] & Auto [car] & Motto [motto] & Panne [mishap] \\
\hline Morchel [morel] & Pilz [mushroom] & Hund [dog] & Morgen [morning] & Jacke [jacket] \\
\hline $\begin{array}{l}\text { Champignon } \\
\text { [mushroom }]\end{array}$ & Pilz [mushroom] & Hund [dog] & Shampoo [shampoo] & Motto [motto] \\
\hline Jacht [yacht] & Schiff [ship] & Pilz [mushroom] & Jacke [jacket] & Morgen [morning] \\
\hline Fähre [ferry] & Schiff [ship] & Pilz [mushroom] & Fährte [trail] & Nacken [neck] \\
\hline Viper [viper] & Schlange [snake] & Trommel [drum] & Visum [visa] & Feile [file] \\
\hline Natter [adder] & Schlange [snake] & Trommel [drum] & Nacken [neck] & Fährte [trail] \\
\hline Pauke [bass drum] & Trommel [drum] & Fisch [fish] & Pause [pause] & Spind [locker] \\
\hline Bongo [bongo] & Trommel [drum] & Fisch [fish] & Bombe [bomb] & Karte [card] \\
\hline Meise [titmouse] & Vogel [bird] & Blume [flower] & Meile [mile] & Schimmer [glimmer] \\
\hline Spatz [sparrow] & Vogel [bird] & Blume [flower] & Spalt [slit] & Wippe [seesaw] \\
\hline
\end{tabular}

Note-Approximate English translations are given in brackets. Bas, basic-level name; Bas-Unr, unrelated to the basic-level name; Sub-Rel, phonologically related to the subordinate-level target name; Sub-Unr, phonologically unrelated to the subordinate-level target name.

\section{APPENDIX C \\ Basic-Level Target Names, Subordinate-Level Name Distractors, and Distractors Phonologically Related and Phonologically Unrelated to the (Nonpreferred) Basic-Level Target Names Used in Experiment 4}

\begin{tabular}{|c|c|c|c|c|}
\hline $\begin{array}{l}\text { Basic-Level } \\
\text { Target Name }\end{array}$ & Sub & Sub-Unr & Bas-Rel & Bas-Unr \\
\hline Auto [car] & Trabi [Trabant] & Bube [jack] & Aula [assembly hall] & Pudding [pudding] \\
\hline Auto [car] & Käfer [Beetle] & Palme [palm] & Aula [assembly hall] & Pudding [pudding] \\
\hline Baum [tree] & Palme [palm] & Käfer [Beetle] & Bauer [farmer] & Hunger [hunger] \\
\hline Baum [tree] & Tanne [fir] & Möwe [seagull] & Bauer [farmer] & Hunger [hunger] \\
\hline Blume [flower] & Rose [rose] & Dackel [dachshund] & Blutung [bleeding] & Kante [edge] \\
\hline Blume [flower] & Tulpe [tulip] & Gondel [gondola] & Blutung [bleeding] & Kante [edge] \\
\hline Boot [boat] & Gondel [gondola] & Tanne [fir] & Bogen [bow] & Stimme [voice] \\
\hline Boot [boat] & Kanu [canoe] & Tulpe [tulip] & Bogen [bow] & Stimme [voice] \\
\hline Fisch [fish] & Aal [eel] & Kuli [ballpoint pen] & Finger [finger] & Bauer [farmer] \\
\hline Fisch [fish] & Hai [shark] & Barbie [Barbie] & Finger [finger] & Bauer [farmer] \\
\hline Hund [dog] & Dackel [dachshund] & Rose [rose] & Hunger [hunger] & Bogen [bow] \\
\hline Hund [dog] & Pudel [poodle] & Kanu [canoe] & Hunger [hunger] & Bogen [bow] \\
\hline Karte [card] & Bube [jack] & Trabi [Trabant] & Kante [edge] & Foto [photo] \\
\hline Karte [card] & Dame [queen] & Füller [fountain pen] & Kante [edge] & Foto [photo] \\
\hline Puppe [doll] & Barbie [Barbie] & Hai [shark] & Pudding [pudding] & Finger [finger] \\
\hline Puppe [doll] & $\begin{array}{l}\text { Matroschka } \\
\text { [nesting doll] }\end{array}$ & Specht [woodpecker] & Pudding [pudding] & Finger [finger] \\
\hline Stift [pen] & Füller [fountain pen] & Pudel [poodle] & Stimme [voice] & Aula [assembly hall] \\
\hline Stift [pen] & Kuli [ballpoint pen] & Aal [eel] & Stimme [voice] & Aula [assembly hall] \\
\hline Vogel [bird] & Möwe [seagull] & Dame [queen] & Foto [photo] & Blutung [bleeding] \\
\hline Vogel [bird] & Specht [woodpecker] & $\begin{array}{l}\text { Matroschka } \\
\text { [nesting doll] }\end{array}$ & Foto [photo] & Blutung [bleeding] \\
\hline
\end{tabular}

Note-Approximate English translations are given in brackets. Sub, subordinate-level name; Sub-Unr, unrelated to subordinate-level name; Bas-Rel, phonologically related to the basic-level target name; Bas-Unr, phonologically unrelated to the basic-level target name. 


\begin{tabular}{|c|c|c|c|c|}
\hline \multicolumn{5}{|c|}{$\begin{array}{c}\text { APPENDIX D } \\
\text { Subordinate-Level Target Names, Basic-Level Name Distractors, and Distractors } \\
\text { Phonologically Related and Phonologically Unrelated to the (Preferred) } \\
\text { Subordinate-Level Target Names Used in Experiment } 5\end{array}$} \\
\hline $\begin{array}{c}\text { Subordinate-Level } \\
\text { Target Name }\end{array}$ & Bas & Bas-Unr & Sub-Rel & Sub-Unr \\
\hline Trabi [Trabant] & Auto [car] & Puppe [doll] & Trafo [transformer] & Puder [powder] \\
\hline Käfer [Beetle] & Auto [car] & Puppe [doll] & Käfig [cage] & Bude [booth] \\
\hline Palme [palm] & Baum [tree] & Hund [dog] & Paste [paste] & Käfig [cage] \\
\hline Tanne [fir] & Baum [tree] & Hund [dog] & Tasche [bag] & Gockel [cock] \\
\hline Rose [rose] & Blume [flower] & Karte [card] & Rodel [sled] & Möbel [furniture] \\
\hline Tulpe [tulip] & Blume [flower] & Karte [card] & Tunnel [tunnel] & Kabel $[$ cable] \\
\hline Gondel [gondola] & Boot [boat] & Stift [pen] & Gockel [cock] & Tasche [bag] \\
\hline Kanu [canoe] & Boot [boat] & Stift [pen] & Kabel [cable] & Fürstin [princess] \\
\hline Aal [eel] & Fisch [fish] & Baum [tree] & Ader [vein] & Paste [paste] \\
\hline Hai [shark] & Fisch [fish] & Baum [tree] & Heizung [heater] & Matte [mat] \\
\hline Dackel [dachshund] & Hund [dog] & Boot [boat] & Dattel [date] & Spende [donation] \\
\hline Pudel [poodle] & Hund [dog] & Boot [boat] & Puder [powder] & Ader [vein] \\
\hline Bube [jack] & Karte [card] & Vogel [bird] & Bude [booth] & Trafo [transformer] \\
\hline Dame [queen] & Karte [card] & Vogel [bird] & Datum [date] & Tunnel [tunnel] \\
\hline Barbie [Barbie] & Puppe [doll] & Fisch [fish] & Barke [barque] & Heizung [heater] \\
\hline $\begin{array}{l}\text { Matroschka } \\
\text { [nesting doll] }\end{array}$ & Puppe [doll] & Fisch [fish] & Matte [mat] & Rodel [sled] \\
\hline Füller [fountain pen] & Stift [pen] & Auto [car] & Fürstin [princess] & Barke [barque] \\
\hline Kuli [ballpoint pen] & Stift [pen] & Auto [car] & Kuchen [cake] & Dattel [date] \\
\hline Möwe [seagull] & Vogel [bird] & Blume [flower] & Möbel [furniture] & Datum [date] \\
\hline Specht [woodpecker] & Vogel [bird] & Blume [flower] & Spende [donation] & Kuchen [cake] \\
\hline
\end{tabular}

(Manuscript received March 19, 2003;

revision accepted for publication October 7, 2004.) 